\title{
Review on residual stress in selective laser melting additive manufacturing of alloy parts
}

\author{
Ze-Chen Fang ${ }^{\mathrm{a}, \mathrm{b}}$, Zhi-Lin $\mathrm{Wu}^{\mathrm{a}}$, Chen-Guang Huang ${ }^{\mathrm{b}}$, Chen-Wu Wu $\mathrm{Wu}^{\mathrm{b}, *}$ \\ ${ }^{a}$ School of Mechanical Engineering, Nanjing University of Science and Technology, Nanjing 210094, China \\ ${ }^{\mathrm{b}}$ Institute of Mechanics, Chinese Academy of Sciences, Beijing 100190, China
}

\section{H I G H L I G H T S}

- The research on residual stress arising in additive manufacturing by SLM are reviewed.

- The advantages and disadvantages of mainstream research methods are analyzed.

- New concepts on controlling the residual stress in alloy parts by SLM are proposed.

\section{A R T I C L E I N F O}

\section{Keywords:}

SLM

Residual stress

Modeling

Characterizing

Adjusting

\begin{abstract}
A B S T R A C T
The undesirable residual stress accumulated in the parts during the melting and solidification of the metal powder layer by layer retards the further application of the selective laser melting (SLM) process. This paper focuses on reviewing the recent illuminating achievements about physical modeling, experimental characterizing, and active adjusting of the residual stress in the parts fabricated by SLM. The advantages and disadvantages of the mainstream and emerging models or approaches are further analyzed. Based on the status and prospect of the relative techniques, a series of conceptual methods are discussed on mitigating residual stress to make some practical inspiration for developing a systematical residual stress balancing technique for SLM.
\end{abstract}

\section{Introduction}

The selective laser melting (SLM) of metal/alloy powder has become one of the most fascinating and promising rapid prototyping technologies due to its potential contribution to the quickly development of aviation, aerospace, medical equipment, automobile manufacturing, and such prominent industrial fields [1-3]. Benefiting from its inherent advantages, the SLM is afforded enormous opportunities as follows:

- The practical application is extending from ordinary structural parts to multi-scale complex key components [4-6].

- The part material microstructures are evolving from single homogeneous to multi-material gradient hybrid [7-12].

- The production concept is changing from bottom-up design to topdown design for satisfying structure integration, functionalization, and optimization [13-16].

However, such opportunities are accompanied with great challenges, of which the most important is the mechanical quality control of the parts. The repeated heating and cooling of the material, with status from powder to solid, make the SLM is intrinsically a non-equilibrium thermodynamic process. Therefore, it is inevitable that non-uniform microstructure, non-uniform thermal plasticity, and phase change plasticity would co-exist within the part. Macroscopically speaking, there is always relatively large residual stress that could lead to deformation and cracking, which is the very puzzle for the quality control of the parts produced by SLM.

\subsection{Effect of residual stress}

The most significant result from residual stress is the microscopic defect and macroscopic failure of the part formed by SLM [17-19], although it could also be accurately designed to increase material hardness and fatigue performance in some classic technique.

As shown in Fig. 1(a) and (b), the non-uniform residual stress accumulated layer by layer resulted in cracking of the parts by SLM, which is common in different kinds of materials such as Inconel-718 alloy and Ti-6Al-4V [20,21]. Fig. 1(c) shows that the cracking could

\footnotetext{
* Corresponding author at: No. 15 Beisihuanxi Road, Beijing 100190, China.

E-mail addresses: chenwuwu@imech.ac.cn, c.w.wu@outlook.com (C.-W. Wu).
} 
(a)

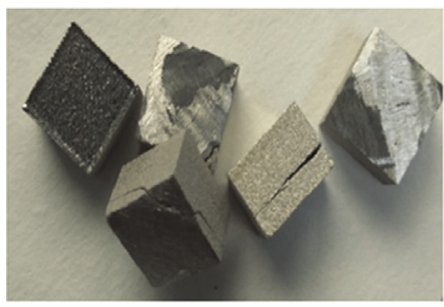

(b)

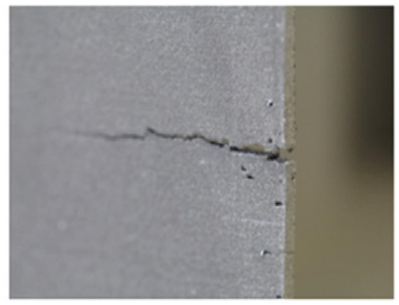

(c)

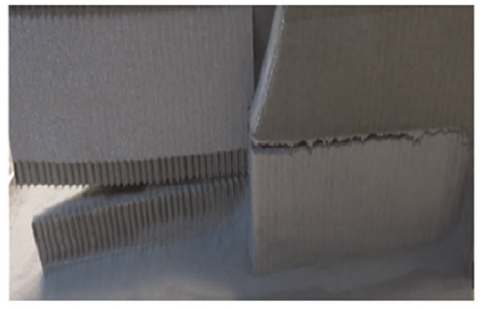

(d)

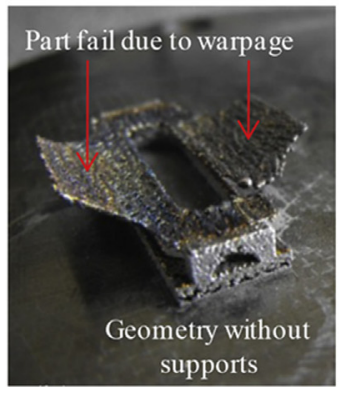

(e)

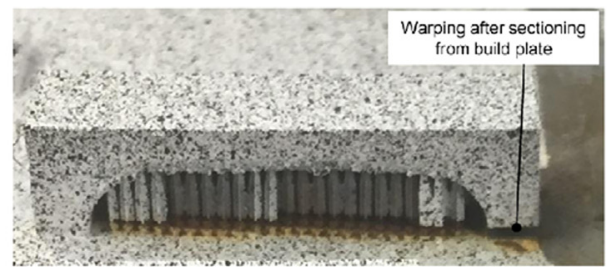

(f)

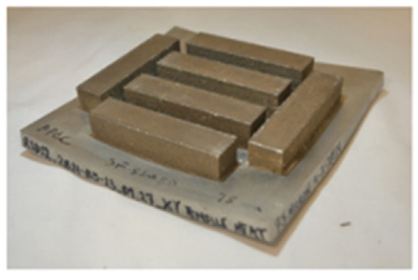

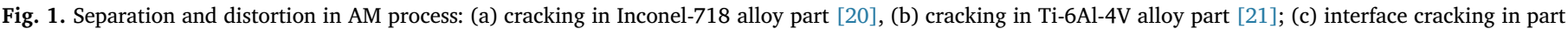

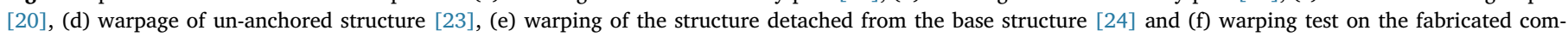
ponents [25].

also arise at the interface between the build platform and the sample due to the excessive thermal contraction of the material during solidification and solid-state phase changing [20]. Similarly, such delamination is frequently observed at the interface between the support components and the derivative part [22]. For the thin-wall parts, like as that in Fig. 1(d), the warping of the structure during the process without adjoining base is also a typical failure [23]. Otherwise, the distortion of the part after being separated from the base as shown in Fig. 1(e) and (f) would reduce the quality and then the productivity of the SLM parts $[24,25]$. It is reported that these frustrating effects are especially significant in such structures as copings, overhanging, bridging [24], thin-walling [6,26], and other complex components $[4,27,28]$. What's cannot be neglected, during the powder scraping process, excessive deformation of the parts will cause damage to the powder supplier.

In many cases, the self-equilibrium residual stresses pose potential threats to the mechanical properties of the materials [29] and the reliability of the parts $[30,31]$ (like as the damages as shown in Fig. 2), even if the distortions of SLM structure are within the allowable range. The residual stress will be released or redistributed during the longterm service life of the work piece, which can lead to fatigue crack $[29,32,33]$, brittle fracture $[34,35]$ and stress corrosion failure $[30,36]$. Leuders et al. $[33,37]$ found that residual stress was the main factor of fatigue crack growth. Critical mechanical properties such as high cycle fatigue strength of the part by SLM still remain below that of the forging

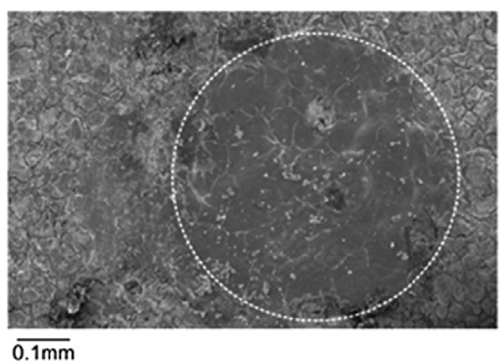

Fig. 2. Effects of residual stress on the stress corrosion cracking in a specimen treated by pulsed-laser irradiation [30].
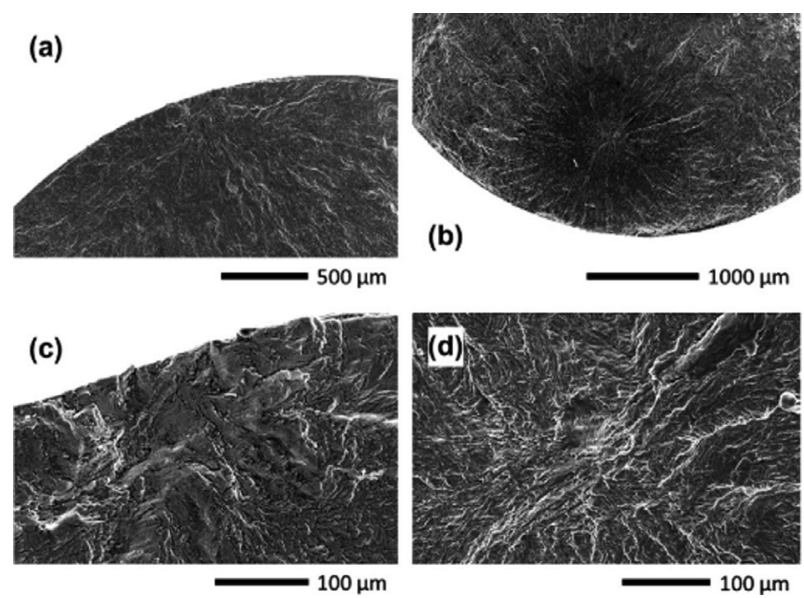

Fig. 3. Morphology of fatigue crack in specimens experienced high cycle loadings [33].

part due to the high residual stress even after post-treatment of hot isostatic pressing (HIP) and open-die forging [1]. As a visual example, Fig. 3 shows the morphology of the fatigue crack surface in the SLM/ HIP specimen subjected to loading of cycling stress of amplitude $620 \mathrm{MPa}$.

\subsection{Origin of residual stress}

The powder as well as solidified phase in the SLM process have experienced cyclic, intense, unsteady heating and cooling that generate extremely complex phase transformation field, various self-restraint boundaries and therefore complicated thermal stress field [27,38,39]. The unsteady thermodynamic state of the solidified phase in SLM process is very similar to that of the material during laser welding (multi-pass welding) [40,41]. Based on the analogous thermal-mechanical conditions, the knowledge on the arising of the residual stress in laser welding could provide much useful reference for the SLM.

A deeper understanding of the physical mechanism on residual stress is the footing stone of the active controlling on it $[38,42-44]$. As 


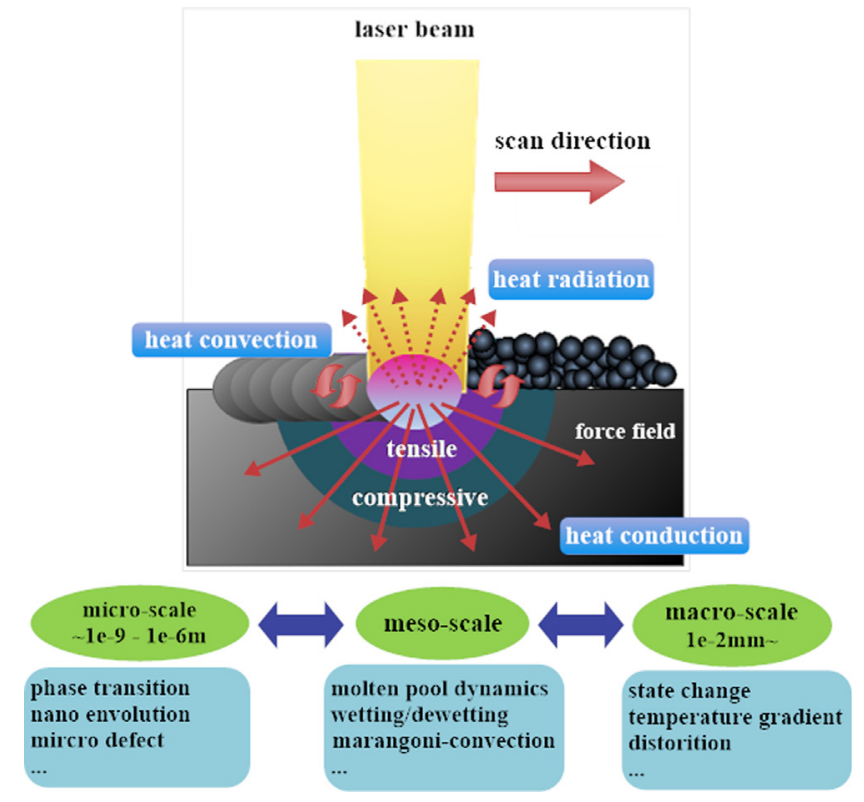

Fig. 4. Sketch of the Multi-physics field in SLM.

shown in Fig. 4, the multi-physical fields dominating the SLM process are coupled in multiple spatial and temporal scales, accompanied with the interactions between the laser and the discrete powder, molten pool or solidified phase $[45,46]$.

Mercelis and Kruth [18] proposed the critical temperature gradient mechanism (TGM) and cooling phase mode that clearly explains the origin of residual stress in the part by SLM at the macro scale [47]. The laser with high energy intensity will rapidly melt the powder layer within beam spot and thermal expansion of the solidified phase occurs under the action of the laser heating. As the beam spot moving, the previously heated region begins to cool and shrink. Meanwhile, such shrinkage is constrained by the previously deposited material, which give rise to a tensile residual stress in those region. Most previously deposited materials surrounding will undergo a cycle of re-melting and re-solidification. With the cyclic layer-by-layer deposition, compressive stress would continuously accumulate in the interior to balance out with the tensile stress distributed near the surface area accounting for the thermos-elastic-plastic deformation of the solidified phase. Through the TGM model, Shi et al. [48] accurately obtained the bending angle along the $y$-axis of laser forming thin plate based on heat transfer theory and elastoplastic mechanics.

A series of mathematical models have been developed to roughly estimate thermal stress for specific material [49-52]. Gusarov, Pavlov, and Smurov [19] have studied the stress in material subjected to single track laser scanning via thermo-elastic modelling and experimental verification. It is found that the maximum tensile stress in the transverse direction is about twice that of the longitudinal (scanning) direction, and the maximum tensile residual stress appears in the remelting region along the longitudinal direction. Such distributional characteristic of the stress accounts for the cracking pattern observed in the experiment. Moreover, it is revealed that the state of residual stress depends on the comparison of ambient temperature to the material melting temperature, which could inspire some active controlling strategy.

Fig. 5 illustrates the overall thermos-mechanical coupling characteristic of the SLM process, which is so sophisticated that the residual stress control is unrealistic if only the macro thermo-elastic model is utilized [53,54]. Therefore, it is required to explore multi-scale numerical simulation accompanied with novel stress measurement, on which many enlightening achievements have emerged and on which a literature review as systematic as possible is in urgent need.

\section{Theoretical modeling}

Strong nonlinearity in multi-physics and large deformations have brought great obstacles to the modeling of the SLM process. Nevertheless, numerical models have gained widespread favor by relatively higher efficiency and lower consumption compared to experimental techniques in decades [54-59]. Not only can it compute the temperature field [54,55] and stress field [56], but also be helpful for both procedure parametric analysis $[21,57,58]$ and numerical verification.

\subsection{Continuum thermal-mechanical model}

Many simplified models have been established on the sequentially coupled thermo-mechanical process of SLM through finite element $[25,60]$ or finite volume $[7,61,62]$ methods, which are thought to be common and validated today. Table 1 lists summarily the latest typical numerical simulations on the parts of various materials based on the sequentially coupled FEM and FVM, most of which evaluate temperature, residual stress as well as deformation. Some numerical results [63] have been validated by the test of neutron diffraction, which further reveal a significant stress redistribution in the relaxed specimen as shown in Fig. 6. Besides, the stress in the top layer is found much lower than the interface layer due to the permitted freedom of deformation.

\subsubsection{Model development}

Lately, there constantly emerges some innovative ideas for the continuum model. Combining the model with metallurgical analysis, Yang et al. [65] predicted the microstructure, hardness, residual stress field, and overall deformation of the samples by laser powder bed fusion (PBF). The results revealed that the residual stress and deformation depended on the overall stiffness of the structure, and the lump-pass method is recommended for layered heating modeling. Li et al. [56] proposed a three-dimensional FEM model considering the phase transition and volume shrinkage during the multi-track multi-layer SLM process. The temperature and stress fields of the AISI $316 \mathrm{~L}$ stainless steel part are illustrated in Figs. 7 and 8, respectively. Smith et al. [64] employed computational phase diagram thermodynamics (CALPHAD) in the thermos-mechanical analysis via finite element method, by which the microstructure, thermal deformation, thermal stress and the residual stress were obtained preliminarily. Similarly, the Cellular Automata Model was introduced to a three-dimension finite-volume model in order to simulate the SLM process and the grain evolution in a multimaterial parts [7]. In any case, it is shown that more reliable conclusions can be drawn by the FEM/FVM approach combined with other related techniques.

\subsubsection{Parameter acquirement}

The physical origin of residual stress has been explained by the critical temperature gradient mechanism [21]. Furthermore, the residual stress and distortion have been validated to be dependent on part geometry [83], material property (e.g., thermal expansion coefficient, elastic modulus, yield strength and so on) $[54,65,68]$, powder layer thickness [22] as well as scan strategy [72,84,85].

Tian et al. [80] numerically simulated the temperature field of large-scale aluminum welding parts and reduced the deformation significantly through the optimization of process parameters. Wu et al. [79] assessed the effect of laser irradiation time on temperature field and residual stress of AlSi10Mg components fabricated by SLM. Similar work could be found in the investigation of thermal behavior with finite element model by ANSYS [81]. Results show that the maximum temperature gradient along molten pool depth direction increase nonlinearly with the laser power but decrease with scanning speed. Through a nearly quantitative assessment with digital image correlation and neutron diffraction, it is [86] verified that the increase of laser energy density (energy per unit length) make a positive influence on 


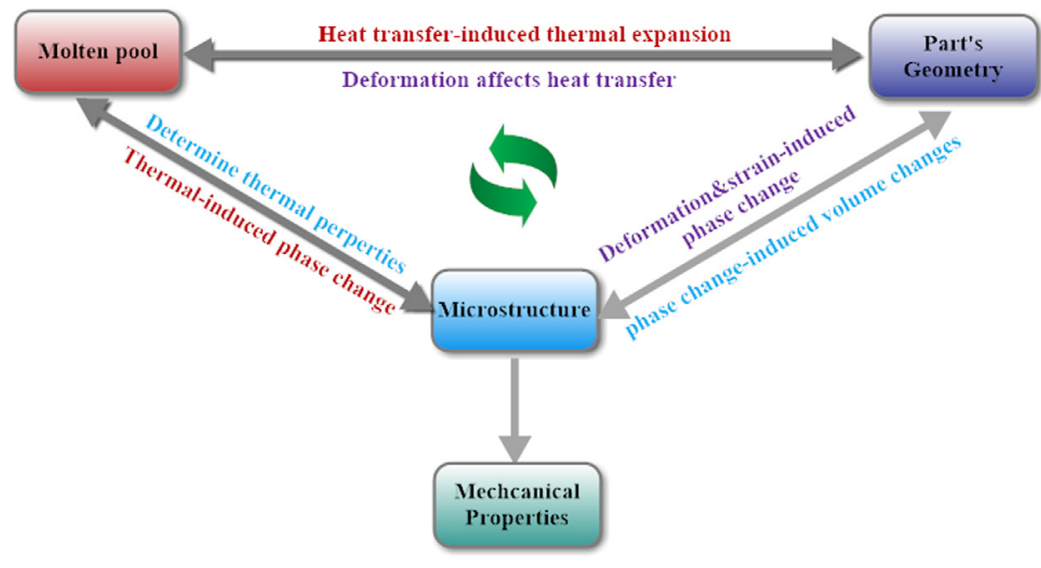

Fig. 5. Thermo-mechanical coupling of the SLM process.

Table 1

Residual stress simulation by FEM/FVM.

\begin{tabular}{|c|c|c|}
\hline Material & Reference & Platform/method \\
\hline Steel (tool steel/mild steel/SS 316L/low-alloy steel) & {$[22,27,56,60,63-70]$} & ANSYS et al./FEM \\
\hline Inconel 718 & {$[25,71,72]$} & ABAQUS et al./FEM \\
\hline Titanium alloy (Ti-6Al-4V/pure titanium/TNM-B/Ti-SiC/Ti-Ni) & {$[21,27,73-78]$} & MARC et al/FEM \\
\hline Aluminum parts (AlSi10Mg/Aluminum alloy) & [79-81] & ANSYS et al./FEM \\
\hline Multi-material (H13 Steel Layer \& Nickel Layer) & {$[7,62]$} & / FVM \\
\hline Zr-Based Amorphous Alloy & {$[82]$} & ABAQUS/FEM \\
\hline
\end{tabular}

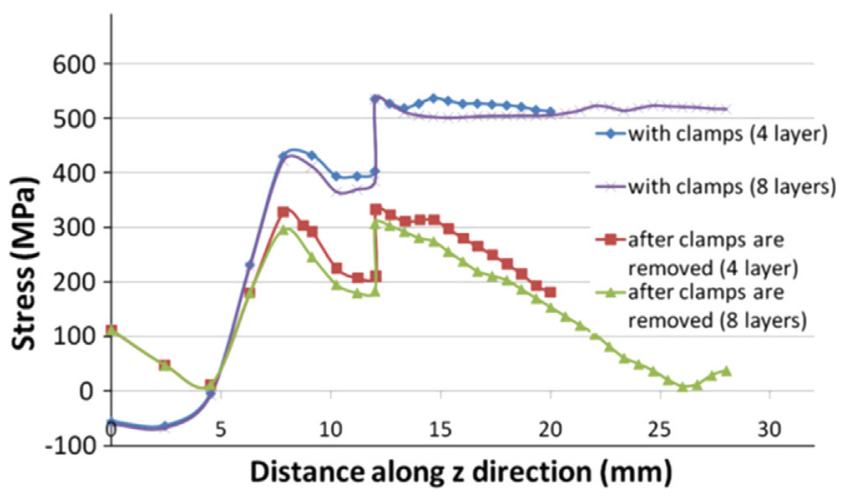

Fig. 6. Example of residual stress predictions [63].

reducing residual stress of 316L Stainless Steel parts.

Meanwhile, Hodge et al. [66] carried out a large number of simulations by changing modeling strategies and process parameter perturbations, which revealed that the pattern of the laser path might significantly influence the residual stress field. PARRY et al. [21] analyzed the influence of scanning strategy on the thermal stress of SLM Ti$6 \mathrm{Al}-4 \mathrm{~V}$ specimens with MARC and found that reducing the length of continuous scanning paths and rotating the scanning direction are beneficial to reducing and levelling the residual stress. The $45^{\circ}$ inclined line scanning has been proved effective in suppressing the deformation along build direction and in-plane residual stress with both FEM simulation [72] and Neutron diffraction measurement [86]. One possible explanation is that $45^{\circ}$ inclined line scanning may create a beneficial dislocation between the maximum thermal stress (scanning direction) and the maximum part dimension [86]. More details specifically concerned about scanning strategy are suggested to see to other relative work $[24,60,67,76]$.

These aforementioned numerical models mainly based on the macroscopic thermo-mechanical method, which can predict the average deformation satisfactorily, while as the capability of parameter optimization seems to have an upper limit [87] as restricted by the analysis scale of continuum model.

\subsection{Multi-scale simulation concept}

The current continuum model on residual stress in SLM parts has major challenges in terms of macro-scale description, cross-scale explanation, and calculation acceleration [40]. For further understanding of the physical mechanism underling the stress evolution, a systematic method based on cross-scale modelling is of fundamental importance and in urgent need. At present, the research on multi-scale modelling is still at an initial developing stage that focuses on the effect of process parameters on residual stress field and related properties of the samples $[88,89]$. The interpretation on basic contribution of micro mechanisms to the macro behaviors is still lacking.

\subsubsection{Mesoscale method}

An early mesoscopic scale model for identifying individual powders in selective beam melting has been developed by Carolin Körner's team based on the Lattice Boltzmann method [90]. Then after, a three-dimensional model [91] considering evaporation and backlash was built by them. In 2016, the same team further implemented a two-dimensional model [92] coupled with the Cellular Automaton Method and Lattice Boltzmann (CALB) Method to simulate grain growth during electron beam selective melting. In the same period, a series of multiphysics models have been established successfully by Lawrence Livermore National Laboratory (using their software ALE3D) $[45,46,59]$. The ESI Software Company applied FVM software CFD-ACE + [93] on many small-scale phenomena analysis such as heat transfer, phase change, melt flow, powder spattering, void formation, and so on. Through an open-source computational fluid dynamics software OpenFOAM, Otto et al. [94] constructed a mesoscale finite volume model including laser-material interaction to simulate heat transfer as well as melt flow. After that, Gürtler et al. [95] improved this model 
(a)

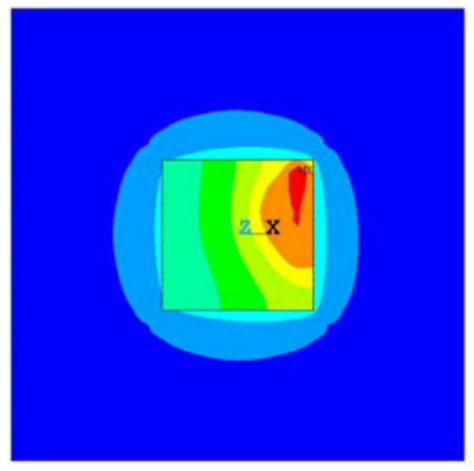

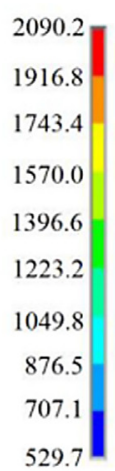

(b)

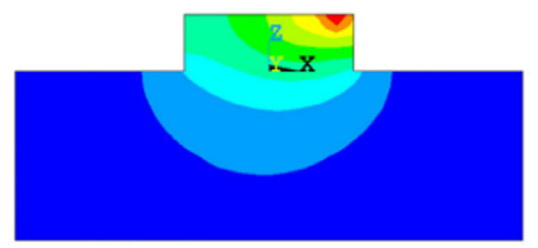

\begin{tabular}{r|}
2090.2 \\
1916.8 \\
1743.4 \\
1570.0 \\
1396.6 \\
1223.2 \\
1049.8 \\
876.5 \\
707.1 \\
529.7
\end{tabular}

(c)

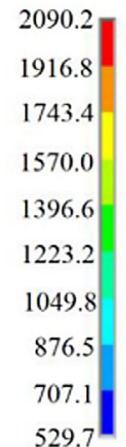

Fig. 7. Temperature contour at (a) $x-y$, (b) $y-z$ and (c) $x-z$ section plane of a four-layer part by SLM [56].

and initially numerically demonstrated the melt pool evolution and void formation in the SLM process. The formation of voids and the realtime surface morphology have also been analyzed through high-speed imaging [96]. It is noteworthy to remark that Zohdi studied continuum and discrete element models systematically on this issue in his monograph [87], wherein a framework has been developed to include multiphysical sub-models to describe the particle deposition at mesoscopic scale. Although, such simulations need not too few scientific details
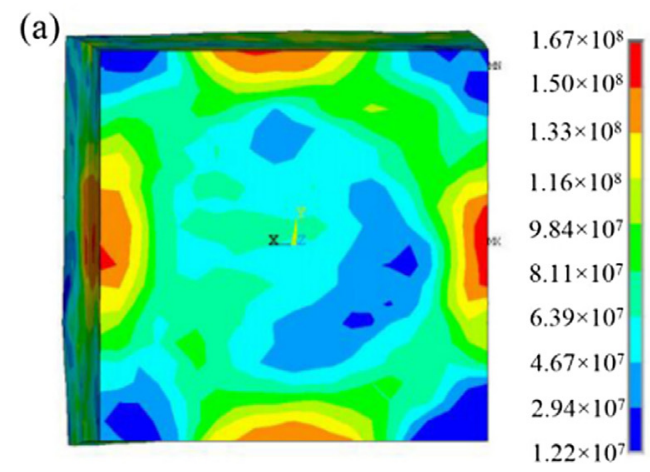

(b)

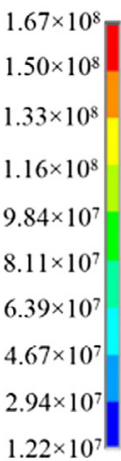

(c)

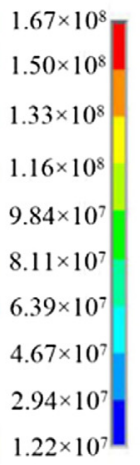

Fig. 8. Residual stress contour at (a) $x-y$, (b) $y-z$, and (c) $x-z$ cross plane of a four-layer part by SLM [56]. 
drawn from micro-scale observations (e.g., TEM, SEM, and so on) [97].

The advantages of the aforementioned mesoscale multi-physical models are outstanding, in particular to interpret such mesoscale phenomenon as void formation and molten pool flow etc. However, there are still many challenges to reveal the physical mechanism thoroughly. For instance, many of the parameters used are still inevitably influenced by human intervention. Besides, the contradiction between calculation accuracy and calculation performance is still hard to balance. Moreover, it is still not easy to simulate the whole multi-layer process today.

\subsubsection{Cross-scale integration}

The microscopic study of the SLM process is thought to be in its infancy [98]. Monte Carlo method has been applied to the simulation of the entire procedure of energy transfer between the energetic free electrons and material atoms $[99,100]$ as well as the micro-scale uncertainty analysis [62]. An equivalent heat source based on the real physical mechanism has been developed for a micro-scale model of laser scan as well [69]. The micro-scale residual stress result was then imported to the macro model to predict part distortion. We strongly recommend a recent comprehensive review [101] that provides a fascinating opportunity for the audience to seize the trend of microscopic modeling for the SLM process. To be noted that the molecular dynamics method was also employed to describe the characteristics of the heat transfer and phase transformation in some preliminary framework that is designed to be linked up with macroscale models and experiments, as shown in Fig. 9 [89].

Considering the advantages of micro-scale model in revealing the physical mechanisms on the material evolution and of macro-scale model in distracting the continuum characteristics and terminal behaviors, the multi-scale modeling [102,103] has incomparable potential to be developed as the most breakthrough technique. Surely, it provides an opportunity to capture more critical details in evaluating residual stress in a part by SLM as well as other basic mechanical performances.

\section{Experimental characterization}

Experimental analysis is the primary method to directly understand the evolution of residual stress in SLM parts. It provides the physical facts for the models, gives verification for the algorithm and thus plays a key role in linking the theoretical prediction, numerical optimization and adjusting decision on residual stress [70,104].

Traditionally, residual stresses can be classified into three categories based on different scales [105], on which the suitable measurement should always be different. Type I residual stress result from macrothermodynamic evolution and has the most significant effect on macromechanical properties of the parts. Type II and type III residual stresses are micro stresses caused by the anisotropy of the grain geometry of the material, point defect and dislocations. Compared with the other two types of residual stresses, type I residual stresses have attracted much more attention. Basically, all of the traditional destructive measures are designed and applied to type I residual stress.

\subsection{Current practical methods}

The measurement of residual stress is an important activity in mechanical engineering and of significant academic meaning, as the enormous influence of the residual stresses is recognized during the forming of most alloy parts. The measurement might have been challenged by the relatively complicated state of residual stress in the SLM parts, wherein high tensile residual stress zone exists on the surface and at the bottom, compressive zone in the interior $[18,27,69,106,107]$.

Various methods have been developed and could be employed quickly in the parts by SLM as shown in Table 2, in which the typical methods are briefly compared especially for residual stress charactering and monitoring. The classic destructive measurement methods, such as hole drilling, groove cutting and contour method etc., have been well developed through a series of application examples $[47,108]$, by which the residual stress distribution along the vertical construction direction can be obtained.

As a good example, Bey Vrancken [39] et al. utilized the contour method to measure the residual stress in compact-tension Ti-6Al-4V specimens produced by SLM, in which the maximum stress are found to be close to the yield stress in this study. In particular, the two-dimensional test results show that residual stresses have a significant influence on the anisotropic mechanical behavior of specimen under tension.

For reasons known to all, non-destructive measurements of residual stress have attracted more attention, in which the method of neutron diffraction is one of the most popular ways and has also been standardized. The latest standard ISO 21432:2019 provides comprehensive guidance for engineering application and further scientific research. As for the operation of neutron diffraction, the material type, sample size, part geometry, testing depth and the magnitude of the expected stress gradient are the critical factors, on which the detailed requirements could be found in the standard documents. Compared with neutron diffraction, the X-ray diffraction method is more recommended for most regular tests due to much lower cost. A thorough comparison of the methods of neutron diffraction and X-ray diffraction could be seen in [142] and [143], both of which

are most widely used for measuring type I residual stress $[63,67,86,88,113,114]$. The Neutron diffraction method can characterize small-scale strain such as strains stored within the grains. In addition, ion beam milling [118] and transmission electron microscopy (TEM) $[119,120]$ can also provide a qualitative prediction of type II and III residual stresses.

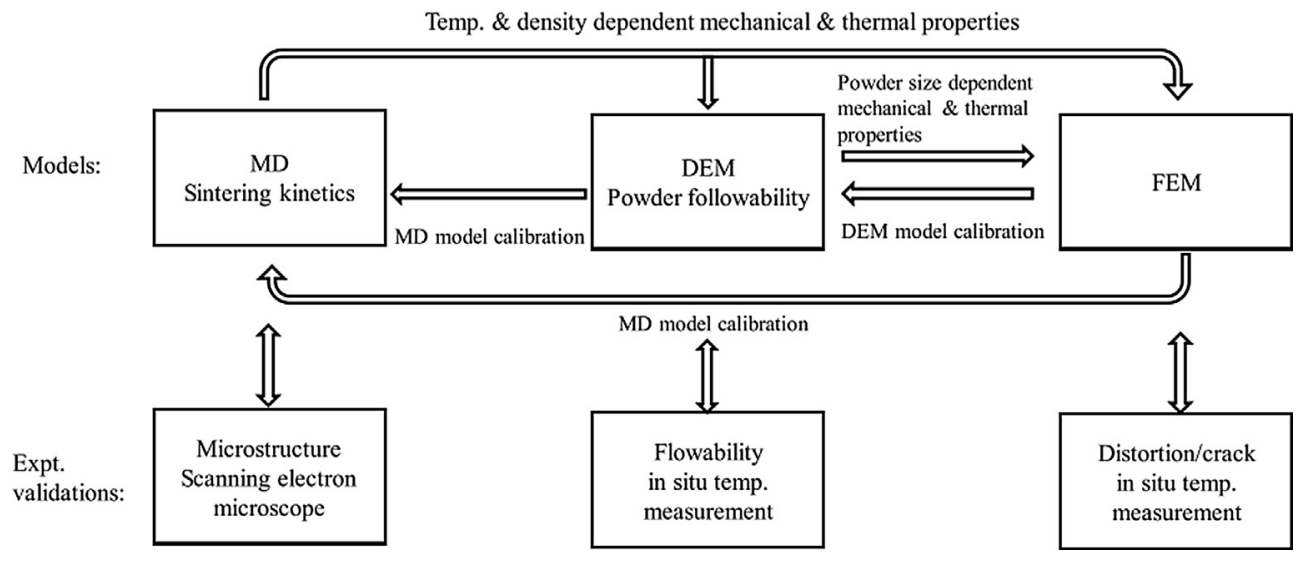

Fig. 9. Concept of coupled modeling framework with experimental validation [89]. 
Table 2

Typical residual stress measurement methods.

\begin{tabular}{|c|c|c|c|c|c|}
\hline Method & Destructive & Min-scale & Real-time & Application & Reference \\
\hline Cutting/hole drilling/bridge curvature method/contour method & $\mathrm{Y}$ & Marco & $\mathrm{N}$ & Measurement & {$[39,108-112]$} \\
\hline X-ray diffraction & $\mathrm{N}$ & Micro & $\mathrm{N}$ & Measurement & {$[67,113-115]$} \\
\hline Neutron diffraction & $\mathrm{N}$ & Micro & $\mathrm{N}$ & Measurement & {$[22,63,86,88,110]$} \\
\hline High-speed X-ray diffraction & $\mathrm{N}$ & Micro & $\mathrm{Y}$ & Monitoring & [116] \\
\hline Ultra-high speed X-ray synchrotron radiation & $\mathrm{N}$ & Micro & $\mathrm{Y}$ & Characterization & [117] \\
\hline Ion beam milling & $\mathrm{Y}$ & Micro & $\mathrm{N}$ & Measurement & {$[118]$} \\
\hline TEM/SEM/OM (optical laser confocal scanning microscope) & $\mathrm{Y}$ & Micro & $\mathrm{N}$ & $\begin{array}{l}\text { Measurement/ } \\
\text { Characterization }\end{array}$ & {$[20,35,96,119-122]$} \\
\hline Digital image correlation (DIC) & $\mathrm{N}$ & Meso & $\mathrm{Y}$ & Measurement & {$[83,86]$} \\
\hline High-speed imaging technology & $\mathrm{N}$ & Meso & $\mathrm{Y}$ & Characterization & {$[96,123,124]$} \\
\hline Micro-CT imaging & $\mathrm{N}$ & Micro & $\mathrm{Y}$ & Characterization & [125-127] \\
\hline $\mathrm{X}$-CT analysis & $\mathrm{N}$ & Meso & $\mathrm{N}$ & Characterization & {$[128,129]$} \\
\hline Laser line scanning profiler & $\mathrm{N}$ & Micro & $\mathrm{Y}$ & Characterization & [130] \\
\hline X-ray micro-diffraction & $\mathrm{N}$ & Micro & Y & Measurement/Monitoring & {$[131]$} \\
\hline Synchrotron energy dispersive & $\mathrm{N}$ & Micro & $\mathrm{N}$ & Characterization & {$[132]$} \\
\hline Thermal sensors (infrared/imaging/pyrometer/thermocouples) & $\mathrm{N}$ & Meso & $\mathrm{Y}$ & Monitoring & {$[104,133-135]$} \\
\hline $\begin{array}{l}\text { Optical method (photodiode/spectrometer/CMOS camera/CCD camera/plume } \\
\text { camera) }\end{array}$ & $\mathrm{N}$ & Meso & $\mathrm{Y}$ & Monitoring & {$[129,136-140]$} \\
\hline Acoustic sensors (ultrasonic) & $\mathrm{N}$ & Macro & Y & Characterization & {$[140,141]$} \\
\hline
\end{tabular}

Y- with that capability, N- without that capability; Micro = Microscale, Meso = Meso-scale and Macro = Macro-scale.

Yadroitsev and Yadroitsava [27] measured the residual stress in the stainless steel and Ti-6Al-4V samples produced by SLM via the method of X-ray diffraction. The results show that the residual stress along the beam scanning direction is larger than that of the perpendicular direction and the residual stress reaches its maximum value at the interface between the sample and the build platform. Due to the thermal gradients, the stresses varied considerably from layer to layer, which is consistent with the similar work $[19,83]$.

Kruth et al. [144] concluded that the appropriate scanning mode resulted in a significant reduction of thermal distortion. In addition to the simulations in Section 2, experimental studies have also demonstrated the effect of scanning strategy and other process parameters tightly related to thermal history on the residual stress field of metal parts by SLM $[20,86,144]$. Based on DIC analysis, Wu et al. [86] stated that for $316 \mathrm{~L}$ stainless steel parts, islands of $3 \times 3 \mathrm{~mm}$ instead of $5 \times 5 \mathrm{~mm}$ is recommended to reduce tensile residual stress. Similarly, Lu et al. [20] investigated the effect of island size on SLM Inconel 718 parts and found that samples with an island size of $5 \times 5 \mathrm{~mm}$ had lower residual stress than samples with an island size of $7 \times 7 \mathrm{~mm}$ or $3 \times 3 \mathrm{~mm}$. At the same time, the geometry of the build platform also has a negligible influence $[18,25,63]$. Based on synchrotron X-ray diffraction, Mishurova et al. [77] attempted to explore the dominant parameters to surface residual stress and discovered that the increase in energy density can reduce residual stress in the subsurface region, which is supported by similar work [86]. There are too many experiments to completely enumerate though we need more to fully understand and control the residual stress in SLM parts.

\subsection{New methodology}

\subsubsection{On the physical mechanism}

There is no doubt that advances in test methods play an important role in understanding the complex physical processes of additive manufacturing metal parts. Matthew et al. [123] revealed the thermal vapor Bernoulli effect on melt flow and powder movement through high-speed imaging technology, thereby providing an approach to control the laser-material interaction and powder melting characteristics. Synchrotron radiation micro-CT imaging technology was employed to achieve the accurate three-dimensional image of internal defects in Co-Cr-Mo samples prepared by SLM [125], which expands the current understanding of mechanism on the metallurgical defects formation. Based on ultra-high-speed X-ray synchrotron radiation equipment, Ross et al. [117] revealed the real formation mechanism of the keyhole phenomenon in laser additive manufacturing. The keyhole phenomenon exists in all ranges of laser power and scanning speed during the powder bed fusion process, in which it's believed that a certain threshold of laser power exists for the transition in heat transfer from conduction mode to keyhole mode. A very recent research employed surface curvature measurements based on Kirchoff plate equations to estimate in-plane residual stress by digital image correlation [83], as shown in Fig. 10.

\subsubsection{On the in-situ detection}

In addition to providing calibration and validation for the computational model, a more practical goal of residual stress testing is to integrate itself into the SLM process control system. With the improvement of computing efficiency, synchrotron radiation-based scanning Laue X-ray micro-diffraction has been developed into a near real-time quantitative imaging technique at the micro and Nano-scale, which may bring new prospects to the control over residual stress [131]. Micro-CT [126], digital image correlation [83] and displacement sensors [104] accompanied with optical [140] and acoustic [141] methods have achieved many meaningful achievements, and further stimulate the detection and analysis of residual stresses.

Lu et al. [104] established an in-situ system integrated thermocouples, infrared imaging sensor, displacement sensor and digital image correlation as shown in Fig. 11. This system could capture the detailed distortion characteristic of the Ti-6Al-4V single-wall parts. Compared with the method of synchrotron radiation, the technique of image analysis is more easily to be implemented as real-time feedback in a closed-loop control system [139]. A similar sensor-based real-time monitoring system can also be found in the similar work [135].

As we know, there are multiple combinations of factors (See Section 5 for details) in the SLM process $[77,112,145]$, each of which is real costs to carry out systematic experimental assessing. That's why the low-cost detection methods based on new principles also attract much laboratory research. For example, Barrett Chris et al. [130] have successfully detected the volume change and spatter phenomena before and after powder melting using high-resolution laser line scanning profiler, which might be one of the potential testing methods tried on by the researchers seeking to describe accurately and control reliably the residual stress in the SLM parts.

\section{Active adjusting}

As described in Sections 2 and 3, optimizing the process parameters 


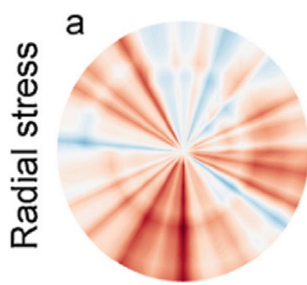

$0^{\circ}$

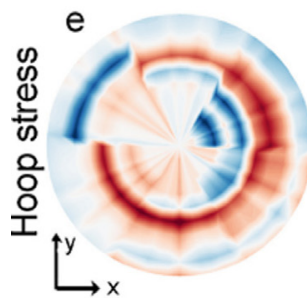

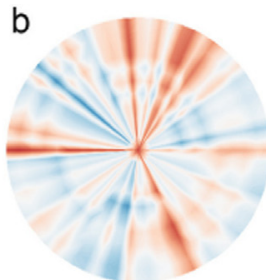

$15^{\circ}$

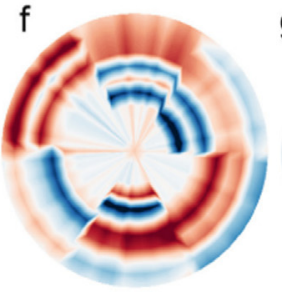

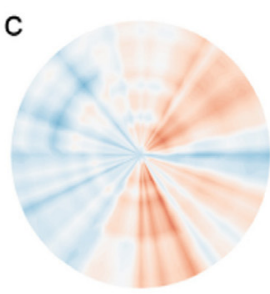

$30^{\circ}$

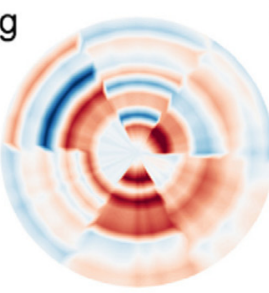

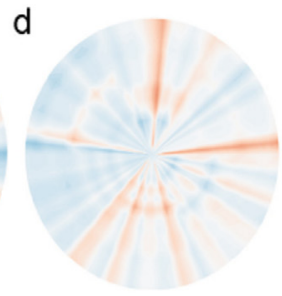

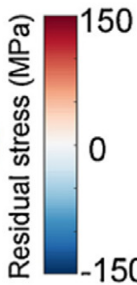

$40^{\circ}$
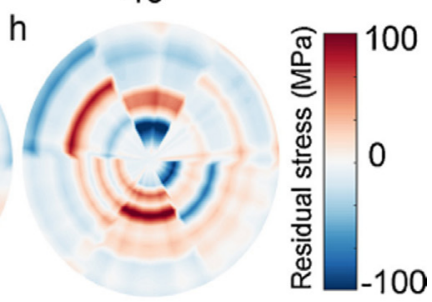

Fig. 10. Residual stress determined by surface geometry [83]

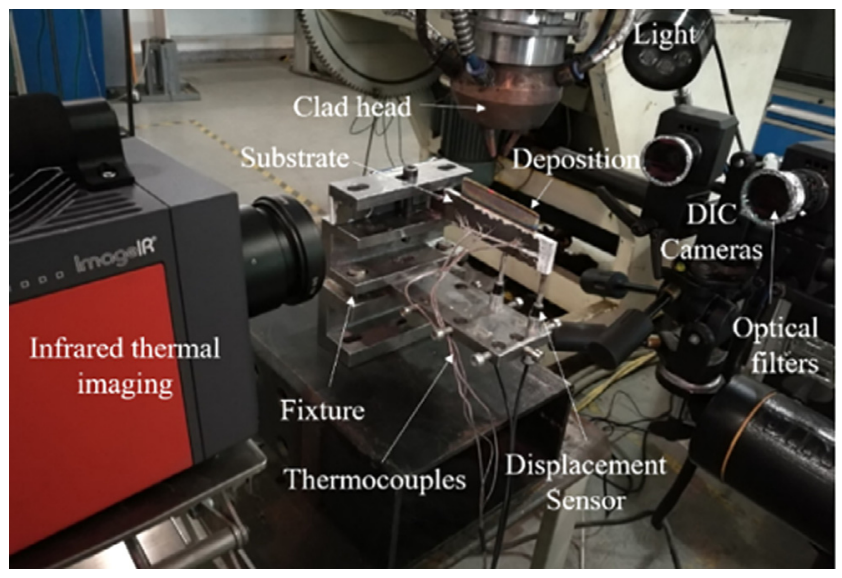

Fig. 11. Monitoring system for in-situ thermo-mechanical field [104]

in the selective laser melting via model prediction and experimental verification can reduce the residual stress in parts to a certain extent, although which is far away from totally suppressing the distortion of the parts due to the strong non-equilibrium nature of the processes. Therefore, it's not difficult to understand that there would be various adjusting methods developed to balance out the undesired residual stress.

\subsection{Preheating of the powder}

Preheating the build platform (supporting structure) [19,22,112,146-149] or powder bed [150-152] to reduce the temperature gradient in the work piece has been one of the most commonly used methods. Most studies have focused on the assessment of the preheating temperature levels for different part geometries and the realized effectiveness. For example, it is reported that preheating the bed to $550^{\circ} \mathrm{C}$, the residual stress in a Ti-6Al-4V bridge sample could be reduced by $46 \%$ and the density increased by $2.88 \%$ [153]. Ali et al. [152] found that the residual tensile stress would disappear if the preheating temperature is higher than $570{ }^{\circ} \mathrm{C}$ and even residual compressive stress will appear in the part, which is beneficial to improving the fatigue performance.

Buchbinder et al. [149] systematically evaluated the geometrical parameter dependence of the effectiveness of bed preheating and revealed that the thickness (part height over the powder bed) of the SLM sample would counteract the effect of bed preheating. It might be easily understood according to the TGM model that a thicker sample means a larger difference in temperature of the topmost powder layer and the power bed, which requires a higher preheating temperature to maintain the initial thermal status of the topmost powder layer.

At the same time, we should know that the bed preheating would also bring about negative influence on the properties of the parts by SLM. For instance, it is found that the significant coarsening of dendrites and the increase of grain size will occur in a SLM part of AlSi10Mg at the bed preheated to $200{ }^{\circ} \mathrm{C}$ due to the reduction in cooling rate, which would of course decrease the hardness of the final part [149]. Generally speaking, the material hardness will be decreased by about $35 \%$ were the preheating temperature increased from $150{ }^{\circ} \mathrm{C}$ to $250{ }^{\circ} \mathrm{C}$. The bed preheating might also change the crystal structure of the material and thus influence its mechanical properties [150] as partially listed in Table 3.

It can be concluded from the results in Table 3 that the bed preheating could reduce the residual stress for most kinds of material, such as aluminum alloy, titanium alloy etc., while might has no significant or

Table 3

Effect of preheating on residual stress and related properties of SLM part.

\begin{tabular}{|c|c|c|c|c|c|}
\hline Material & $\mathrm{T} /{ }^{\circ} \mathrm{C}$ & Stress reduction & Crack reduction & Phase transformation \& Microstructure & Mechanical property \\
\hline Ti-6Al-4V bridge samples [153] & 550 & $46.31 \%$ & / & Oxygen and hydrogen content rose & $2.88 \%$ increasing of relative density \\
\hline Ti-6Al-4V [154] & 400 & $50 \%$ & / & $\beta$ phase partial decomposition & Increasing the hardness, reducing the ductility \\
\hline Ti-6Al-4V-ELI [152] & 570 & $90 \%$ & / & A basket weave $\alpha+\beta$ microstructure & High yield strength of $1176 \mathrm{MPa}$, improving ductility \\
\hline AlSi10Mg thin-walled part [155] & 300 & $83 \%$ & / & / & / \\
\hline M2 tool steel parts [147] & 300 & Less & $\mathrm{Y}$ & Less martensite formation & Maximum density of $99.8 \%$ \\
\hline AlSi10Mg twin cantilever [149] & 250 & $90 \%$ & $\mathrm{Y}$ & grain coarsening & Hardness decrees, lowered yield strength \\
\hline Al7075 [156] & 400 & / & $\mathrm{Y}$ & Prohibiting MgZn2 precipitates & / \\
\hline HastelloyX [156] & 400 & Few & $\mathrm{Y}$ & Grain coarsening in prolonged exposure & Improving relative density combined laser parameter \\
\hline H13 tool steel $[151,156]$ & 400 & Reverse & $\mathrm{Y}$ & Bainitic microstructure & Higher hardness and ultimate tensile strength \\
\hline $\operatorname{CoCr}[156]$ & 400 & Few & Few & Changing texture & Nearly no \\
\hline
\end{tabular}


Table 4

Typical adjusting methods on residual stress.

\begin{tabular}{|c|c|c|c|c|c|}
\hline Measures & Applied Stage & Adaptability & Control effect & Other effects & Maturity \\
\hline Preheating & Pre- & $\begin{array}{l}\text { Limited by material and } \\
\text { geometry }\end{array}$ & Partly & $\begin{array}{l}\text { Crack suppression and phase } \\
\text { transformation }\end{array}$ & Late \\
\hline Annealing & Post- & Powerless to large distortion & Partly & More emphasis on adjusting performance & Late \\
\hline Hot isostatic pressing & Post- & Same as above & Partly & Same as above. & Late \\
\hline Real-time control & Online & Wide & Thorough & $\begin{array}{l}\text { Improving design accuracy and } \\
\text { reliability }\end{array}$ & Preliminary \\
\hline Laser shock processing & Online & Wide & Thorough & Easy to integrate into SLM equipment & Preliminary \\
\hline Integrated forming & Online & Wide & Difficult to quantify & High efficiency & Developing \\
\hline Ultrasonic peening & Post- & Wide & $\begin{array}{l}\text { Little effect on internal } \\
\text { stress }\end{array}$ & Better corrosion resistance & Middle-late \\
\hline $\begin{array}{l}\text { Modulation of material component/ } \\
\text { state }\end{array}$ & Pre- & Limited materials & Thorough & Promote materials and structures design & Preliminary \\
\hline
\end{tabular}

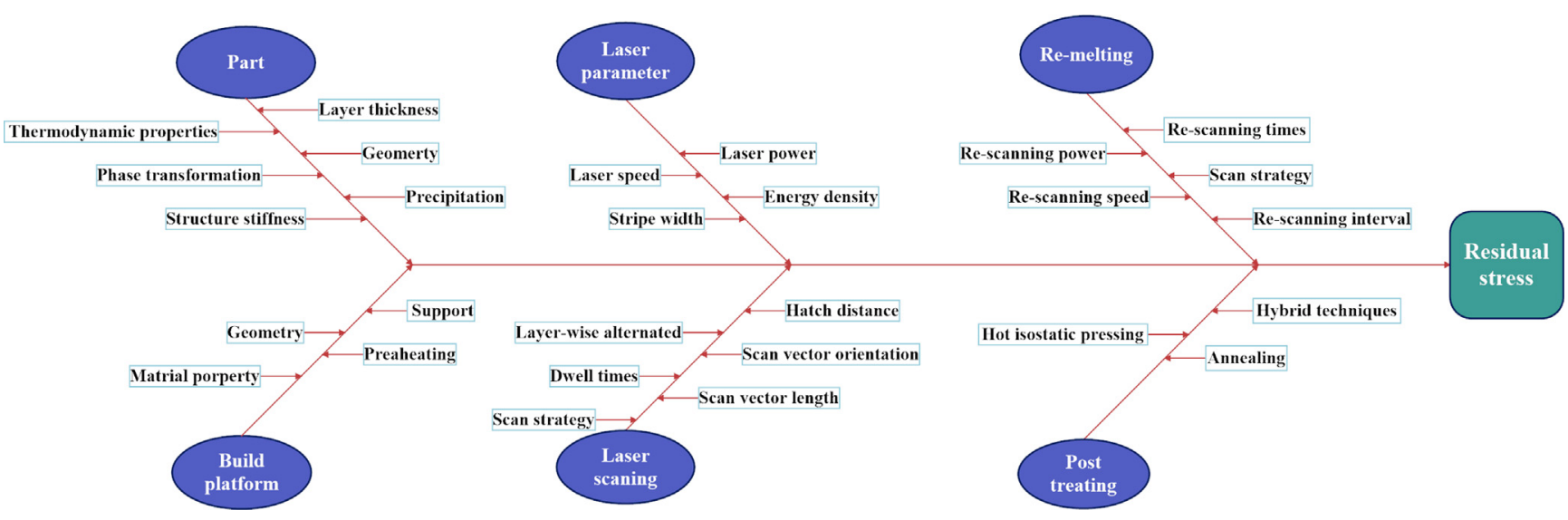

Fig. 12. Diagram of the influencing factors of SLM residual stress.

even reverse outcome for specific super alloys that experiencing adverse phase changes due to the preheating. Therefore, the effects of the preheating on microstructure and mechanical properties of the parts should be comprehensively studied to avoid such counterproductive results.

Now, the preheating temperature is also regarded as one of the SLM parameters and chosen combined with other parameters such as laser energy density, scanning speed and so on, to achieve optimized part performance. For aluminum alloy and titanium alloy samples with thin wall thickness or relatively small height, it's recommended that preheating should be adopted as the current best method to reduce the residual stress. It is also noteworthy that the effect of preheating might be more significant for the process of electron beam melting (EBM) than the SLM [157] due to both the difference in the powder bed and the isolated vacuum chamber for EBM.

\subsection{Heat treatment on the parts}

In addition to the bed preheating, much attention has been drawn by the development and application of other pre-treatment and posttreatment on power or part to change the residual stresses $[119,158]$, in which teat treatment is one of the main methodologies [159-161]. Tomus and $\mathrm{Li}$ etc. $[119,120]$ have observed that heat treatment can significantly reduce the dislocation density in as-built AM parts. Shiomi et al. [38] found that the residual stress in chromium-molybdenum steel parts could be reduced by $70 \%$ after annealing. Actually, the vacuum annealing has also been proved to be effective in reducing residual stresses in the SLM parts of AlSi10Mg and Inconel 625 alloy $[161,162]$. Typically, the combination of hot isostatic pressing and classic heat treatment is also a common approach to improve the stress distribution and product quality $[119,161]$. Again, the probable adverse effects on mechanical properties of the heating and cooling during heat treatment should also be notified [163], as an example while promoting the SLM parts of Ti-6Al-4V to undergo phase transitions (i.e., from $\beta$ grains to lamellar $\alpha+\beta$ ) to counteract residual stresses [47].

\subsection{Real-time control of the process}

Once the stress in the part is large enough to cause plastic deformation or fracture of the material, it is almost impossible to mitigate through post-processing. Hence the stress control during the manufacturing process is very important, especially for large-scale additive manufacturing component constrained heavily [63]. As demonstrated in Section. 3, the means of infrared imaging, high-speed X-ray imaging, micro-diffraction and other optical detecting aided with appropriate image computation algorithms could realize on-site thermal state monitoring of the molten pool, powder layer, deposited layer, temperature field as well as the hot spot or incomplete fusion during melting and solidification. These techniques bring exciting expectations for homogenizing the surface temperature field, reducing thermal gradient and then adjusting residual stress through closed-loop feedback control of input laser energy [136,138,139,164-169].

\subsection{More hybrid techniques}

Bed preheating and heat treatment are common methods to counteract on the residual stress in parts by SLM. However, the effectiveness of these methods is always limited to a great extent. Therefore, it's not hard to image that more hybrid methodologies could be discovered to adjust the residual stress in the SLM parts, which might be combination of classic techniques or inspiration of brand-new concepts.

\subsubsection{Technique combination and integration}

Kalletics et al. [170] discussed the ability of laser shock to balance 
Table 5

Influence factors of residual stress for various SLM material.

\begin{tabular}{|c|c|c|}
\hline Material & Effect & Method \\
\hline \multicolumn{3}{|l|}{ Factors: Part } \\
\hline Al7075 [183] & MgZn2 precipitates need to be prohibited & Experiment \\
\hline Inconel 718 [65] & Residual stress depends on structure stiffness & FEM \\
\hline Ferrous-based material [68] & $\begin{array}{l}\text { Similar coefficients of linear expansion between combing-materials are helpful to resist } \\
\text { residual stress }\end{array}$ & Experiment \\
\hline AlSi10Mg [149] & Lowered yield strength allows plastic deformation at lower equivalent stress & Experiment \\
\hline H13 steel [151] & Compressive stresses generate at surfaces during the martensitic transformation & Experiment \\
\hline AlSi10Mg twin cantilever [149] & The larger bar thickness leads to smaller distortion & Experiment \\
\hline Stainless steel 316L [83] & Larger cone angles developed less residual stress for the inverted-cone part & Experiment \& FEM \\
\hline 316 stainless steel $[18,112]$ & Residual stress increase with the number of layers & Modeling analysis, experiment \\
\hline Tool steel [22], managing steel [184] & Distortion significantly decreased due to larger powder layer thickness & Modeling simulation, experiment \\
\hline \multicolumn{3}{|l|}{ Factors: Build platform } \\
\hline / & The effect of preheating given in Table 3 & / \\
\hline 316 stainless steel [185] & $\begin{array}{l}\text { Lower tooth spacing leads to compressive axial RS. Higher top length leads to compressive } \\
\text { axial RS and tensile in-plane RS }\end{array}$ & FEM \\
\hline 316 stainless steel [18] & A higher height of build platform results in a lower stress level & Model analysis \& experiment \\
\hline \multicolumn{3}{|l|}{ Factors: Laser parameter } \\
\hline Ti-6Al-4V [105] Ti-6Al-4V [47], & Higher laser power, slower scan speed, and smaller stripe width are recommended & Experiment \\
\hline Ti-6Al-4V BCM Sample [153] & $73 \%$ of surface distortion decreased with an increasing of energy density by $27 \%$ & Experiment \\
\hline TiC/Inconel 718 composites [84] & $\begin{array}{l}125 \mathrm{~W} \text { laser power and } 100 \mathrm{~mm} / \mathrm{s} \text { scanning speed obtain sound metallurgical bonding } \\
\text { between layers and tracks }\end{array}$ & FEM \& experiment \\
\hline $\begin{array}{l}\text { 316L Stainless Steel }[86] \text {, Ti6Al-4V prisms } \\
\text { [77] }\end{array}$ & Higher laser density may induce lower residual stresses for parts & FEM, experiment \\
\hline \multicolumn{3}{|l|}{ Factors: Laser scanning } \\
\hline Ti-6Al-4V [21 47], 316 Stainless Steel [112] & $\begin{array}{l}\text { Reducing scan vectors and rotating scan vectors are beneficial to release residual stress } \\
\text { distribution }\end{array}$ & $\begin{array}{l}\text { Simulation/Bridge curvature } \\
\text { method }\end{array}$ \\
\hline Inconel 718 [72], 316L stainless steel [86]. & $\begin{array}{l}45^{\circ} \text { inclined line scanning has been proved effective to reduce the deformation along build } \\
\text { direction and in-plane residual stress }\end{array}$ & FEM \& experiment \\
\hline 316L stainless steel [86], Inconel 718 [20] & $\begin{array}{l}3 \times 3 \mathrm{~mm} \text { island is more recommended for stainless steel, while } 5 \times 5 \mathrm{~mm} \text { island } \\
\text { recommended for Inconel } 718 \text { to reduce residual stress }\end{array}$ & Experiments \\
\hline AlSi10Mg [186] & $\begin{array}{l}\text { The checkerboard scanning strategy dissipates heat faster well and produces fewer defects } \\
\text { and less internal stress than the uniform scanning strategy }\end{array}$ & Experiments \\
\hline Ti-6Al-4V, Inconel 625 [187] & $\begin{array}{l}\text { Distortion and residual stress decrease with dwell times for Inconel 625, which is opposite for } \\
\text { Ti-6Al-4V }\end{array}$ & In situ measurements \\
\hline $\begin{array}{l}\text { Ti6Al-4V prisms [77], 316L stainless steel } \\
\text { [188] }\end{array}$ & Sub-surface residual stress decreases $75 \%$ due to hatch distance decrease to $40 \mu \mathrm{m}$ & synchrotron x-ray diffraction \\
\hline \multicolumn{3}{|l|}{ Factors: Re-melting } \\
\hline Chrome-molybdenum steel [38] & Tensile stress decreases $55 \%$ by laser re-scanning & Experiments \\
\hline Alumina [19] & $\begin{array}{l}\text { The maximum tensile residual stresses arise in the re-melted region along the scanning } \\
\text { direction }\end{array}$ & Modeling analysis \\
\hline Ti-5Al-2.5Sn alloy [111], & $\begin{array}{l}1 \text { cycle laser re-melting on each solidified layer leads to residual stress increasing, while } 2 \text { or } \\
\text { more cycles make principal residual stresses decreasing }\end{array}$ & Experiments \\
\hline AlSi10Mg [189] & Residual stress can be reduced with multiple re-melting & Experiments \\
\hline Factors: Post heat treating is shown in Table 4 & & \\
\hline
\end{tabular}

the residual stress in SLM manufactured parts. It is revealed that if the overlap ratio of the laser spots is high enough, the surface tensile residual stress can be easily converted into a favorable compressive residual stress with a depth exceeding $1 \mathrm{~mm}$. Laser itself is a kind of highefficiency energy source of SLM, so it has natural advantages to be integrated into SLM manufacturing system for real-time control. New insights from welding and other similar processes are also invaluable. Ultrasonic shot peening (UPT) has proven to be an effective method to improve the residual stress distribution in welded structures, which has also shown great potential in stress modification of SLM metal parts [171-173]. The application of UPT in improving the stress corrosion performance of AlSi10Mg SLM specimens has also proved this knowledge [173].

Turning, grinding, shot peening [171], finishing (magnetic fieldassisted finishing [174], laser finishing [175]), etc. will generate compressive residual stresses on the work piece surface and beneath the work piece surface. From this perspective, the joint additive and subtractive manufacturing are expected to mix the characteristics of their respective residual stresses, resulting in unexpected effects of residual stress balance $[174,176]$.

\subsubsection{Microstructure design and optimization}

Microscopically, studying the evolution of phase transitions may be a breakthrough. For example, the effect of filler composition on balancing residual stress was found in welders. Experimental and theoretical calculations indicate that a reasonably designed filler material or powder composition can resist local tensile residual stress by generating compressive strain through solid phase transition during welding or enhanced manufacturing [177-181]. The preheating process also reduces internal compressive residual stresses by favorable phase transitions in some ways, as especially a study [68] revealed that the deformation between bonded materials would be reduced when the linear expansion coefficients are more similar. Therefore, it is strongly recommended that employing thermal effects and phase transitions produces offsetting residual stresses when designing the powder components and SLM process.

As aforementioned, certain types of geometries, such as cobalt chrome dental copings, overhang structure, bridge components, cantilever structure, crowns, etc., require multiple anchors to prevent warpage, which significantly increases the manufacturing cost. Moreover, the anchor will not be able to resist distortions of the part when the stress magnitude is too high and the part would be twisted due to the residual stress after removing the anchors. As an attractive way, in the 
so-called metal eutectic systems, the anchorless selective laser melting (ASLM) or semi-solid state processing (SSP) $[23,182]$ could keep the material of immediately processed layer stay semi-solid state through controlling input laser energy and preheating building platform $[23,182]$ and thus suppressing the residual stress in parts.

The advantages of the main stress adjusting methods are summarized in Table 4 for the sake of convenience, although there is still a lot to be explored for the precise control of residual stress in SLM parts.

\section{Parametrical analysis}

Physical mechanism on thermo-mechanical evolution of material, modeling analysis, experimental measurements and control methods over residual stress in the SLM parts are reviewed in the earlier sections to cover the main factors affecting the final residual stress. These factors are discussed systematically as shown in Fig. 12 in view of parametrical analysis to give some more practical suggestions and references.

More detailed comparison on these factors are further listed in Table 5, which could provide a quick reference for similar processes as well as help immediately catch the characteristic of the residual stress in the SLM parts of typical materials.

Based on the technique comparison as listed in Table 5 , there could be some further recognition and illumination on the issue of residual stress in SLM parts. The yield strength of the material at different temperatures is a crucial parameter to residual stress [149] as the residual stress is resulted from the stored elastic strain energy, which is maintained and constrained by the surrounding plastic deformation in most parts. Some materials are prone to microstructure changes at certain temperatures, which also have a great impact on residual stress. The part geometry is also a critical factor that influences the residual stress through determining the temperature gradient in the parts, for which the good example is that such special structures as overhang and lattice are apt to distortion or cracking due to high temperature gradient.

Even as the bed preheating plays a more important role in controlling residual stress than aimless changing of laser parameters, which has more flexibility in process design. In particular, the nonlinear effects of laser power and scanning speed on residual stress are found in the SLM parts as such two parameters largely determine the size and shape, temperature gradient, wettability and topography of the molten pool. That means, the process defects such as incomplete sintering, spheroidization, crack-like voids and keyhole would be related with the residual stress in very complicated ways $[190,191]$.

Moreover, the laser scanning paths, such as $45^{\circ}$ inclined line scanning in the same layer could generate favorable stress state as the heat dissipation conditions are altered and texture reconstruction realized [188]. Re-melting of the solidified region by subsequent laser heating could smooth the temperature gradient in the solidified layer and thereby reduce residual stress [189]. After all, such crucial factors deserve more specific investigation, which is especially important for parts of complex geometries, special materials or with high requirements in size/shape accuracy and mechanical properties.

\section{Conclusion}

Research on the residual stress in the parts by SLM is in a relatively rapid development stage, while complicated mechanisms are involved in such a strong non-equilibrium multi-physical process. Many meaningful work, such as multi-scale modeling, real-time process detecting, micro-scale experimental characterizing and active stress adjusting have emerged. And some satisfactory results have been achieved for specific process on specific materials, which provide good reference for a new start in technique development. It has been revealed that the overall evolution of stress field is determined by both the microscopic structure and macroscopic surrounding conditions, which requires multi-scale effects to be included in a useful theory. Most of these studies are still in the preliminary stage of qualitative demonstration, which requires the quantitative theoretical models based on real physical mechanism to be developed.

\section{Declaration of Competing Interest}

The authors declare that they have no known competing financial interests or personal relationships that could have appeared to influence the work reported in this paper.

\section{Acknowledgments}

This work was supported by the National Natural Science Foundation of China (Grant No. 11572327), the Strategic Priority Research Program of Chinese Academy of Sciences (Grant No. XDA17030100 \& XDA17030200) and the Postgraduate Research \& Practice Innovation Program of Jiangsu Province (Grant No. KYCX19_0273).

\section{References}

[1] F.G. Arcella, F.H. Froes, Producing titanium aerospace components from powder using laser forming, Jom-J. Miner. Met. Mater. Soc. 52 (5) (2000) 28-30, https:// doi.org/10.1007/s11837-000-0028-x.

[2] C.Y. Yap, C.K. Chua, Z.L. Dong, Z.H. Liu, D.Q. Zhang, L.E. Loh, S.L. Sing, Review of selective laser melting: materials and applications, Appl. Phys. Rev. 2 (4) (2015) 041101, , https://doi.org/10.1063/1.4935926.

[3] R. Mines, Additive Manufacturing Processes and Materials for Metallic Microlattice Structures Using Selective Laser Melting, Electron Beam Melting and Binder Jetting, Metallic Microlattice Structures, Springer, 2019, pp. 17-31.

[4] H.M. Wang, S.Q. Zhang, H.B. Tang, X.J. Tian, D. Liu, Laser additive manufacturing of aerospace large metallic structural components: state of the arts and challenges, international photonics and optoelectronics meetings, Opt. Soc. Am, Wuhan (2012) p. MTh3B.2, https://doi.org/10.1364/LTST.2012.MTh3B.2.

[5] L. Sheng, H. Hassanin, M.M. Attallah, N.J.E. Adkins, K. Essa, The development of TiNi-based negative Poisson's ratio structure using selective laser melting, Acta Mater. 105 (2016) 75-83, https://doi.org/10.1016/j.actamat.2015.12.017.

[6] T. Boegelein, E. Louvis, K. Dawson, G.J. Tatlock, A.R. Jones, Characterisation of a complex thin walled structure fabricated by selective laser melting using a ferritic oxide dispersion strengthened steel, Mater. Charact. 112 (2016) 30-40, https:// doi.org/10.1016/j.matchar.2015.11.021.

[7] S. Mohanty, J.H. Hattel, Laser Additive Manufacturing of multimaterial tool inserts: A simulation-based optimization study, Laser 3d Manuf. Iv 10095 (2017). https://doi.org/10.1117/12.2253600.

[8] D. Grafe, A. Wickberg, M.M. Zieger, M. Wegener, E. Blasco, C. Barner-Kowollik, Adding chemically selective subtraction to multi-material 3D additive manufacturing, Nat. Commun. 9 (1) (2018) 2788, https://doi.org/10.1038/s41467018-05234-0.

[9] J. Koopmann, J. Voigt, T. Niendorf, Additive manufacturing of a steel-ceramic multi-material by selective laser melting, Metallurg. Mater. Trans. B-Process Metall. Mater. Process. Sci. 50 (2) (2019) 1042-1051, https://doi.org/10.1007/ s11663-019-01523-1.

[10] A.G. Demir, B. Previtali, Multi-material selective laser melting of Fe/Al-12Si components, Manuf. Lett. 11 (2017) 8-11, https://doi.org/10.1016/j.mfglet.2017. 01.002 .

[11] S. Yin, X.C. Yan, C.Y. Chen, R. Jenkins, M. Liu, R. Lupoi, Hybrid additive manufacturing of Al-Ti-6Al-4V functionally graded materials with selective laser melting and cold spraying, J. Mater. Process. Technol. 255 (2018) 650-655, https://doi.org/10.1016/j.jmatprotec.2018.01.015.

[12] Y.-T. Kao, Y. Zhang, J. Wang, B.L. Tai, Loading-unloading cycles of 3D-printing built bi-material structures with ceramic and elastomer, ASME 2016 11th International Manufacturing Science and Engineering Conference, 2016, https:// doi.org/10.1115/msec2016-8791.

[13] H. Hassanin, F. Modica, M.A. El-Sayed, J. Liu, K. Essa, Manufacturing of Ti-6Al-4V micro-implantable parts using hybrid selective laser melting and micro-electrical discharge machining, Adv. Eng. Mater. 18 (9) (2016) 1544-1549, https://doi.org/ 10.1002/adem.201600172.

[14] M. Fousova, D. Vojtech, J. Kubasek, E. Jablonska, J. Fojt, Promising characteristics of gradient porosity Ti-6Al-4V alloy prepared by SLM process, J. Mech. Behav. Biomed. Mater. 69 (Complete) (2017) 368-376, https://doi.org/10.1016/j jmbbm.2017.01.043.

[15] C. Yan, L. Hao, A. Hussein, P. Young, Ti-6Al-4V triply periodic minimal surface structures for bone implants fabricated via selective laser melting, J. Mech. Behav. Biomed. Mater. 51 (2015) 61-73, https://doi.org/10.1016/j.jmbbm.2015.06.024.

[16] U. Kostevsek, T. Brajlih, J. Balic, Z. Kadivnik, I. Drstvensek, Development of productivity estimation model for mass-customized production by selective laser melting, Rapid Prototyp. J. 24 (3) (2018) 670-676, https://doi.org/10.1108/Rpj06-2017-0120.

[17] S. Koric, B.G. Thomas, Thermo-mechanical models of steel solidification based on 
two elastic visco-plastic constitutive laws, J. Mater. Process. Technol. 197 (1-3) (2008) 408-418, https://doi.org/10.1016/j.jmatprotec.2007.06.060.

[18] P. Mercelis, J.P. Kruth, Residual stresses in selective laser sintering and selective laser melting, Rapid Prototyp. J. 12 (5) (2006) 254-265, https://doi.org/10.1108/ 13552540610707013.

[19] A.V. Gusarov, M. Pavlov, I. Smurov, Residual stresses at laser surface remelting and additive manufacturing, lasers in manufacturing 2011, in: Proceedings of the Sixth International Wlt Conference on Lasers in Manufacturing, vol 12, Pt A 12(1) (2011) 248-254. https://doi.org/10.1016/j.phpro.2011.03.032.

[20] Y.J. Lu, S.Q. Wu, Y.L. Gan, T.T. Huang, C.G. Yang, J.J. Lin, J.X. Lin, Study on the microstructure, mechanical property and residual stress of SLM Inconel-718 alloy manufactured by differing island scanning strategy, Opt. Laser Technol. 75 (2015) 197-206, https://doi.org/10.1016/j.optlastec.2015.07.009.

[21] L. Parry, I.A. Ashcroft, R.D. Wildman, Understanding the effect of laser scan strategy on residual stress in selective laser melting through thermo-mechanical simulation, Addit. Manuf. 12 (2016) 1-15, https://doi.org/10.1016/j.addma. 2016.05.014.

[22] M.F. Zaeh, G. Branner, Investigations on residual stresses and deformations in selective laser melting, Prod. Eng. Res. Devel. 4 (1) (2010) 35-45, https://doi.org/ 10.1007/s11740-009-0192-y.

[23] P. Vora, K. Mumtaz, I. Todd, N. Hopkinson, AlSi12 in-situ alloy formation and residual stress reduction using anchorless selective laser melting, Addit. Manuf. 7 (2015) 12-19, https://doi.org/10.1016/j.addma.2015.06.003.

[24] R.J. Williams, C.M. Davies, P.A. Hooper, A pragmatic part scale model for residual stress and distortion prediction in powder bed fusion, Addit. Manuf. 22 (2018) 416-425, https://doi.org/10.1016/j.addma.2018.05.038.

[25] P. Prabhakar, W.J. Sames, R. Dehoff, S.S. Babu, Computational modeling of residual stress formation during the electron beam melting process for Inconel 718, Addit. Manuf. 7 (2015) 83-91, https://doi.org/10.1016/j.addma.2015.03.003.

[26] A.F. Zhang, B.L. Qi, B.F. Shi, D.C. Li, Effect of curvature radius on the residual stress of thin-walled parts in laser direct forming, Int. J. Adv. Manuf. Technol. 79 (1-4) (2015) 81-88, https://doi.org/10.1007/s00170-014-6769-4.

[27] I. Yadroitsev, I. Yadroitsava, Evaluation of residual stress in stainless steel 316L and Ti-6Al-4V samples produced by selective laser melting, Virt. Phys. Prototyp. 10 (2) (2015) 67-76, https://doi.org/10.1080/17452759.2015.1026045.

[28] J. Whiting, J. Fox, Characterization of feedstock in the powder bed fusion process: sources of variation in particle size distribution and the factors that influence them, International Solid Freeform Fabrication Symposium Austin, Texas, USA, (2016).

[29] A.K. Syed, B. Ahmad, H. Guo, T. Machry, D. Eatock, J. Meyer, M.E. Fitzpatrick, $X$. Zhang, An experimental study of residual stress and direction-dependence of fatigue crack growth behaviour in as-built and stress-relieved selective-lasermelted Ti-6Al-4V, Mater. Sci. Eng. A-Struct. Mater. Properties Microstruct. Process. 755 (2019) 246-257, https://doi.org/10.1016/j.msea.2019.04.023.

[30] S. Eto, Y. Miura, J. Tani, T. Fujii, Effect of residual stress induced by pulsed-laser irradiation on initiation of chloride stress corrosion cracking in stainless steel, Mater. Sci. Eng. A-Struct. Mater. Propert. Microstruct. Process. 590 (2014) 433-439, https://doi.org/10.1016/j.msea.2013.10.066.

[31] N.J. Harrison, I. Todd, K. Mumtaz, Reduction of micro-cracking in nickel superalloys processed by Selective Laser Melting: a fundamental alloy design approach, Acta Mater. 94 (2015) 59-68, https://doi.org/10.1016/j.actamat.2015.04.035.

[32] C. Rans, J. Michielssen, M. Walker, W.D. Wang, L. 't Hoen-Velterop, Beyond the orthogonal: on the influence of build orientation on fatigue crack growth in SLM Ti-6Al-4V, Int. J. Fatigue 116 (2018) 344-354. https://doi.org/10.1016/j.ijfatigue.2018.06.038.

[33] S. Leuders, M. Thöne, A. Riemer, T. Niendorf, T. Tröster, H.A. Richard, H.J. Maier, On the mechanical behaviour of titanium alloy TiAl6V4 manufactured by selective laser melting: fatigue resistance and crack growth performance, Int. J. Fatigue 48 (2013) 300-307, https://doi.org/10.1016/j.ijfatigue.2012.11.011.

[34] B. Van Hooreweder, D. Moens, R. Boonen, J.-P. Kruth, P. Sas, Analysis of fracture toughness and crack propagation of Ti-6Al-4V produced by selective laser melting, Adv. Eng. Mater. 14 (1-2) (2012) 92-97, https://doi.org/10.1002/adem. 201100233.

[35] G.Q. Zhang, Y.Q. Yang, H. Lin, C.H. Song, Z.M. Zhang, Study on the quality and performance of CoCrMo alloy parts manufactured by selective laser melting, J. Mater. Eng. Perform. 26 (6) (2017) 2869-2877, https://doi.org/10.1007/s11665017-2716-5.

[36] X.Y. Lou, M.A. Othon, R.B. Rebak, Corrosion fatigue crack growth of laser additively-manufactured 316L stainless steel in high temperature water, Corros. Sci. 127 (2017) 120-130, https://doi.org/10.1016/j.corsci.2017.08.023.

[37] A. Riemer, S. Leuders, M. Thone, H.A. Richard, T. Troster, T. Niendorf, On the fatigue crack growth behavior in 316L stainless steel manufactured by selective laser melting, Eng. Fract. Mech. 120 (4) (2014) 15-25, https://doi.org/10.1016/j. engfracmech.2014.03.008.

[38] M. Shiomi, K. Osakada, K. Nakamura, T. Yamashita, F. Abe, Residual stress within metallic model made by selective laser melting process, Cirp Ann.-Manuf. Technol. 53 (1) (2004) 195-198, https://doi.org/10.1016/S0007-8506(07)60677-5.

[39] B. Vrancken, V. Cain, R. Knutsen, J. Van Humbeeck, Residual stress via the contour method in compact tension specimens produced via selective laser melting, Scr. Mater. 87 (87) (2014) 29-32, https://doi.org/10.1016/j.scriptamat.2014.05. 016.

[40] A. De, T. DebRoy, A perspective on residual stresses in welding, Sci. Technol. Weld. Join. 16 (3) (2011) 204-208, https://doi.org/10.1179/ $136217111 \times 12978476537783$.

[41] S. Kou, Welding Metallurgy, second ed., Hoboken, New Jersey, 2003, pp. 1-29.

[42] A.H. Nickel, D.M. Barnett, F.B. Prinz, Thermal stresses and deposition patterns in layered manufacturing, Mater. Sci. Eng., A 317 (1) (2001) 59-64, https://doi.org/ 10.1016/S0921-5093(01)01179-0.

[43] P.J. Withers, H.K.D.H. Bhadeshia, Residual stress. Part 2 - nature and origins, Mater. Sci. Technol. 17 (4) (2013) 366-375, https://doi.org/10.1179/ 026708301101510087

[44] M. Rombouts, J.P. Kruth, L. Froyen, P. Mercelis, Fundamentals of selective laser melting of alloyed steel powders, Cirp Ann.-Manuf. Technol. 55 (1) (2006) 187-192, https://doi.org/10.1016/S0007-8506(07)60395-3.

[45] W. King, A.T. Anderson, R.M. Ferencz, N.E. Hodge, C. Kamath, S.A. Khairallah, Overview of modelling and simulation of metal powder bed fusion process a Lawrence Livermore National Laboratory, Mater. Sci. Technol. 31 (8) (2015) 957-968, https://doi.org/10.1179/1743284714y.0000000728.

[46] S.A. Khairallah, A.T. Anderson, A. Rubenchik, W.E. King, Laser powder-bed fusion additive manufacturing: Physics of complex melt flow and formation mechanisms of pores, spatter, and denudation zones, Acta Mater. 108 (2016) 36-45, https:// doi.org/10.1016/j.actamat.2016.02.014.

[47] B. Vrancken, Study of residual stresses in selective laser melting, KU Leuven, 2016

[48] Y.J. Shi, H. Shen, Z.Q. Yao, J. Hu, Temperature gradient mechanism in laser forming of thin plates, Opt. Laser Technol. 39 (4) (2007) 858-863, https://doi org/10.1016/j.optlastec.2005.12.006.

[49] S. Ghosh, J. Choi, Modeling and experimental verification of transient/residual stresses and microstructure formation in multi-layer laser aided DMD process, J. Heat Transf.-Trans. ASME 128 (7) (2006) 662-679, https://doi.org/10.1115/1. 2194037.

[50] F. Brückner, D. Lepski, E. Beyer, Modeling the influence of process parameters and additional heat sources on residual stresses in laser cladding, J. Therm. Spray Technol. 16 (3) (2007) 355-373, https://doi.org/10.1007/s11666-007-9026-7.

[51] F. Brückner, D. Lepski, E. Beyer, Calculation of stresses in two-and three-dimensional structures generated by induction assisted laser cladding, Proc. LIM (2009) $115-120$

[52] A.M. Kamat, Y.T. Pei, An analytical method to predict and compensate for residual stress-induced deformation in overhanging regions of internal channels fabricated using powder bed fusion, Addit. Manuf. 29 (2019) 100796. https://doi.org/UNSP 100796 10.1016/j.addma.2019.100796.

[53] C. Agelet de Saracibar, On the formulation of coupled thermoplastic problems with phase-change, Int. J. Plast. 15 (1) (1999) 1-34, https://doi.org/10.1016/ s0749-6419(98)00055-2.

[54] L.E. Lindgren, A. Lundback, M. Fisk, Thermo-mechanics and microstructure evolution in manufacturing simulations, J. Therm. Stresses 36 (6) (2013) 564-588, https://doi.org/10.1080/01495739.2013.784121.

[55] Y. Yang, M.F. Knol, F. van Keulen, C. Ayas, A semi-analytical thermal modelling approach for selective laser melting, Addit. Manuf. 21 (2018) 284-297, https:// doi.org/10.1016/j.addma.2018.03.002.

[56] Y.L. Li, K. Zhou, P.F. Tan, S.B. Tor, C.K. Chua, K.F. Leong, Modeling temperature and residual stress fields in selective laser melting, Int. J. Mech. Sci. 136 (2018) 24-35, https://doi.org/10.1016/j.ijmecsci.2017.12.001.

[57] H. Ali, H. Ghadbeigi, K. Mumtaz, Residual stress development in selective lasermelted Ti-6Al-4V: a parametric thermal modelling approach, Int. J. Adv. Manuf. Technol. 97 (5-8) (2018) 2621-2633, https://doi.org/10.1007/s00170-0182104-9.

[58] D.H. Dai, D.D. Gu, H. Zhang, J.P. Xiong, C.L. Ma, C. Hong, R. Poprawe, Influence of scan strategy and molten pool configuration on microstructures and tensile properties of selective laser melting additive manufactured aluminum based parts, Opt. Laser Technol. 99 (2018) 91-100, https://doi.org/10.1016/j.optlastec.2017. 08.015 .

[59] S.A. Khairallah, A. Anderson, Mesoscopic simulation model of selective laser melting of stainless steel powder, J. Mater. Process. Technol. 214 (11) (2014) 2627-2636, https://doi.org/10.1016/j.jmatprotec.2014.06.001.

[60] Z. Dong, Y. Liu, W. Wen, J. Ge, J. Liang, Effect of hatch spacing on melt pool and as-built quality during selective laser melting of stainless steel: modeling and experimental approaches, Materials 12 (1) (2018) 50, https://doi.org/10.3390/ ma12010050.

[61] F. Verhaeghe, T. Craeghs, J. Heulens, L. Pandelaers, A pragmatic model for selective laser melting with evaporation, Acta Mater. 57 (20) (2009) 6006-6012, https://doi.org/10.1016/j.actamat.2009.08.027.

[62] S. Mohanty, J.H. Hattel, Numerical model based reliability estimation of selective laser melting process, Physics Procedia 56 (2014) 379-389, https://doi.org/10. 1016/j.phpro.2014.08.135.

[63] J. Ding, P. Colegrove, J. Mehnen, S. Ganguly, P.M.S. Almeida, F. Wang, S. Williams, Thermo-mechanical analysis of Wire and Arc Additive Laye Manufacturing process on large multi-layer parts, Comput. Mater. Sci. 50 (12) (2011) 3315-3322, https://doi.org/10.1016/j.commatsci.2011.06.023.

[64] J. Smith, W. Xiong, J. Cao, W.K. Liu, Thermodynamically consistent microstructure prediction of additively manufactured materials, Comput. Mech. 57 (3) (2016) 359-370, https://doi.org/10.1007/s00466-015-1243-1.

[65] Y.P. Yang, M. Jamshidinia, P. Boulware, S.M. Kelly, Prediction of microstructure, residual stress, and deformation in laser powder bed fusion process, Comput. Mech. 61 (5) (2018) 599-615, https://doi.org/10.1007/s00466-017-1528-7.

[66] N.E. Hodge, R.M. Ferencz, R.M. Vignes, Experimental comparison of residua stresses for a thermomechanical model for the simulation of selective lase melting, Addit. Manuf. 12 (2016) 159-168, https://doi.org/10.1016/j.addma. 2016.05.011.

[67] L. Mugwagwa, D. Dimitrov, S. Matope, I. Yadroitsev, Evaluation of the impact of scanning strategies on residual stresses in selective laser melting, Int. J. Adv. Manuf. Technol. 102 (5-8) (2019) 2441-2450, https://doi.org/10.1007/s00170019-03396-9. 
[68] T. Furumoto, R. Ogura, K. Hishida, A. Hosokawa, T. Koyano, S. Abe, T. Ueda, Study on deformation restraining of metal structure fabricated by selective lase melting, J. Mater. Process. Technol. 245 (2017) 207-214, https://doi.org/10. 1016/j.jmatprotec.2017.02.017.

[69] C. Li, C.H. Fu, Y.B. Guo, F.Z. Fang, A multiscale modeling approach for fast prediction of part distortion in selective laser melting, J. Mater. Process. Technol. 229 (2016) 703-712, https://doi.org/10.1016/j.jmatprotec.2015.10.022.

[70] Y. Liu, J. Zhang, Z.C. Pang, Numerical and experimental investigation into the subsequent thermal cycling during selective laser melting of multi-layer 316L stainless steel, Opt. Laser Technol. 98 (2018) 23-32, https://doi.org/10.1016/j. optlastec.2017.07.034.

[71] C. Seidel, M.F. Zaeh, M. Wunderer, J. Weirather, T.A. Krol, M. Ott, Simulation of the laser beam melting process - approaches for an efficient modelling of the beam-material interaction, in: 8th International Conference on Digital Enterprise Technology - Det 2014 Disruptive Innovation in Manufacturing Engineering Towards the 4th Industrial Revolution 25 (2014) 146-153. https://doi.org/10. 1016/j.procir.2014.10.023.

[72] B. Cheng, S. Shrestha, K.V. Chou, Stress and deformation evaluations of scanning strategy effect in selective laser melting, Addit. Manuf. 12 (2016) 240-251, https://doi.org/10.1016/j addma.2016.05.007.

[73] Y.L. Li, D.D. Gu, Thermal behavior during selective laser melting of commercially pure titanium powder: Numerical simulation and experimental study, Addit. Manuf. 1-4 (2014) 99-109, https://doi.org/10.1016/j.addma.2014.09.001.

[74] L. Löber, F.P. Schimansky, U. Kühn, F. Pyczak, J. Eckert, Selective laser melting of a beta-solidifying TNM-B1 titanium aluminide alloy, J. Mater. Process. Technol. 214 (9) (2014) 1852-1860, https://doi.org/10.1016/j.jmatprotec.2014.04.002.

[75] P. Krakhmalev, I. Yadroitsev, Microstructure and properties of intermetallic composite coatings fabricated by selective laser melting of Ti-SiC powder mixtures, Intermetallics 46 (2014) 147-155, https://doi.org/10.1016/j.intermet. 2013.11.012.

[76] J. Song, W.H. Wu, L. Zhang, B.B. He, L. Lu, X.Q. Ni, Q.L. Long, G.L. Zhu, Role of scanning strategy on residual stress distribution in Ti-6Al-4V alloy prepared by selective laser melting, Optik 170 (2018) 342-352, https://doi.org/10.1016/j. ijleo.2018.05.128.

[77] T. Mishurova, K. Artzt, J. Haubrich, G. Requena, G. Bruno, New aspects about the search for the most relevant parameters optimizing SLM materials, Addit. Manuf. 25 (2019) 325-334, https://doi.org/10.1016/j.addma.2018.11.023.

[78] D.D. Gu, B.B. He, Finite element simulation and experimental investigation of residual stresses in selective laser melted Ti-Ni shape memory alloy, Comput. Mater. Sci. 117 (2016) 221-232, https://doi.org/10.1016/j.commatsci.2016.01. 044.

[79] J.J. Wu, L.Z. Wang, X.G. An, Numerical analysis of residual stress evolution of AlSi10Mg manufactured by selective laser melting, Optik 137 (2017) 65-78, https://doi.org/10.1016/j.ijleo.2017.02.060.

[80] Y.H. Tian, C.Q. Wang, D.Y. Zhu, Y. Zhou, Finite element modeling of electron beam welding of a large complex $\mathrm{Al}$ alloy structure by parallel computations, $\mathrm{J}$ Mater. Process. Technol. 199 (1-3) (2008) 41-48, https://doi.org/10.1016/j. jmatprotec. 2007.07.045.

[81] Y.L. Li, D.D. Gu, Parametric analysis of thermal behavior during selective laser melting additive manufacturing of aluminum alloy powder, Mater. Des. 63 (2014) 856-867, https://doi.org/10.1016/j.matdes.2014.07.006.

[82] W. Xing, D. Ouyang, N. Li, L. Liu, Estimation of Residual Stress in Selective Laser Melting of a Zr-Based Amorphous Alloy, Materials (Basel) 11(8) (2018) 1480https://doi.org/10.3390/ma11081480.

[83] J.L. Bartlett, B.P. Groom, J. Burdick, D. Henkel, X.D. Li, Revealing mechanisms of residual stress development in additive manufacturing via digital image correlation, Addit. Manuf. 22 (2018) 1-12, https://doi.org/10.1016/j.addma.2018.04. 025.

[84] Q.M. Shi, D.D. Gu, M.J. Xia, S.N. Cao, T. Rong, Effects of laser processing parameters on thermal behavior and melting/solidification mechanism during selective laser melting of TiC/Inconel 718 composites, Opt. Laser Technol. 84 (2016) 9-22, https://doi.org/10.1016/j.optlastec.2016.04.009.

[85] X.Z. Shi, S.Y. Ma, C.M. Liu, Q.R. Wu, Parameter optimization for Ti-47Al-2Cr-2Nb in selective laser melting based on geometric characteristics of single scan tracks, Opt. Laser Technol. 90 (2017) 71-79, https://doi.org/10.1016/j.optlastec.2016. 11.002.

[86] A.S. Wu, D.W. Brown, M. Kumar, G.F. Gallegos, W.E. King, An experimental investigation into additive manufacturing-induced residual stresses in $316 \mathrm{~L}$ stainless steel, Metallurg. Mater. Trans. A-Phys. Metall. Mater.Sci. 45a (13) (2014) 6260-6270, https://doi.org/10.1007/s11661-014-2549-x.

[87] T.I. Zohdi, Modeling and Simulation of Functionalized Materials for Additive Manufacturing and 3D Printing: Continuous and Discrete Media: Continuum and Discrete Element Methods, Springer, 2017.

[88] D.D. Gu, C.L. Ma, M.J. Xia, D.H. Dai, Q.M. Shi, A multiscale understanding of the thermodynamic and kinetic mechanisms of laser additive manufacturing, Engineering 3 (5) (2017) 675-684, https://doi.org/10.1016/J.Eng.2017.05.011.

[89] J. Zhang, Y. Zhang, W.H. Lee, L. Wu, H.-H. Choi, Y.-G. Jung, A multi-scale multiphysics modeling framework of laser powder bed fusion additive manufacturing process, Met. Powder Rep. 73 (3) (2018) 151-157, https://doi.org/10.1016/j. mprp.2018.01.003.

[90] C. Körner, E. Attar, P. Heinl, Mesoscopic simulation of selective beam melting processes, J. Mater. Process. Technol. 211 (6) (2011) 978-987, https://doi.org/10. 1016/j.jmatprotec. 2010.12.016.

[91] R. Ammer, M. Markl, U. Ljungblad, C. Korner, U. Rude, Simulating fast electron beam melting with a parallel thermal free surface lattice Boltzmann method, Comput. Math. Appl. 67 (2) (2014) 318-330, https://doi.org/10.1016/j.camwa.
2013.10.001.

[92] A. Rai, M. Markl, C. Korner, A coupled Cellular Automaton-Lattice Boltzmann model for grain structure simulation during additive manufacturing, Comput. Mater. Sci. 124 (2016) 37-48, https://doi.org/10.1016/j.commatsci.2016.07.005.

[93] M. Megahed, H.W. Mindt, N. N'Dri, H.Z. Duan, O. Desmaison, Metal additivemanufacturing process and residual stress modeling, Integr. Mater. Manuf. Innov. 5 (1) (2016) 61-93, https://doi.org/10.1186/s40192-016-0047-2.

[94] A. Otto, H. Koch, R.G. Vazquez, Multiphysical simulation of laser material processing, Laser Assisted Net Shape Eng. 7 (Lane 2012) 39 (2012) 843-852, https:// doi.org/10.1016/j.phpro.2012.10.109.

[95] F.J. Gürtler, M. Karg, K.H. Leitz, M. Schmidt, Simulation of laser beam melting of steel powders using the three-dimensional volume of fluid method, Phys. Procedia 41 (2013) 881-886, https://doi.org/10.1016/j.phpro.2013.03.162.

[96] C.L. Qiu, C. Panwisawas, M. Ward, H.C. Basoalto, J.W. Brooks, M.M. Attallah, On the role of melt flow into the surface structure and porosity development during selective laser melting, Acta Mater. 96 (2015) 72-79, https://doi.org/10.1016/j. actamat.2015.06.004.

[97] A. Perron, J.D. Roehling, P.E.A. Turchi, J.-L. Fattebert, J.T. McKeown, Matching time and spatial scales of rapid solidification: Dynamic TEM experiments coupled to CALPHAD-informed phase-field simulations, Modell. Simul. Mater. Sci. Eng 26 (1) (2017).

[98] N. Tamanna, R. Crouch, S. Naher, Progress in numerical simulation of the laser cladding process, Opt. Lasers Eng. 122 (2019) 151-163, https://doi.org/10.1016/ j.optlaseng.2019.05.026.

[99] W.T. Yan, J. Smith, W.J. Ge, F. Lin, W.K. Liu, Multiscale modeling of electron beam and substrate interaction: a new heat source model, Comput. Mech. 56 (2) (2015) 265-276, https://doi.org/10.1007/s00466-015-1170-1.

[100] Y. Zhang, X.H. Xiao, J. Zhang, Kinetic Monte Carlo simulation of sintering behavior of additively manufactured stainless steel powder particles using reconstructed microstructures from synchrotron X-ray microtomography, Res. Phys. 13 (2019), https://doi.org/10.1016/j.rinp.2019.102336.

[101] J.H.K. Tan, S.L. Sing, W.Y. Yeong, Microstructure modelling for metallic additive manufacturing: a review, Virt. Phys. Prototyp. 15 (1) (2020) 87-105, https://doi org $/ 10.1080 / 17452759.2019 .1677345$

[102] D.D. Gu, D.H. Dai, M.J. Xia, C.L. Ma, Cross-scale physical mechanisms for structure and performance control of metal components processed by selective laser melting additive manufacturing, J. Nanjing Univ. Aeronaut. Astronaut. 49 (5) (2017) 645-652 https://doi.org/10.16356/j.1005-2615.2017.05.007.

[103] M. Markl, C. Korner, Multiscale modeling of powder bed-based additive manufacturing, Annu. Rev. Mater. Res. 46 (1) (2016) 93-123, https://doi.org/10.1146/ annurev-matsci-070115-032158.

[104] X. Lu, X. Lin, M. Chiumenti, M. Cervera, Y. Hu, X. Ji, L. Ma, W. Huang, In situ measurements and thermo-mechanical simulation of Ti-6Al-4V laser solid forming processes, Int. J. Mech. Sci. 153-154 (2019) 119-130, https://doi.org/10. 1016/j.ijmecsci.2019.01.043.

[105] P.J. Withers, H.K.D.H. Bhadeshia, Residual stress part $1-$ measurement techniques, Mater. Sci. Technol. 17 (4) (2001) 355-365, https://doi.org/10.1179/ 026708301101509980.

[106] R.J. Moat, A.J. Pinkerton, L. Li, P.J. Withers, M. Preuss, Residual stresses in laser direct metal deposited Waspaloy, Mater. Sci. Eng. A-Struct. Mater. Propert. Microstruct. Process. 528 (6) (2011) 2288-2298, https://doi.org/10.1016/j.msea. 2010.12.010.

[107] C. Li, Z.Y. Liu, X.Y. Fang, Y.B. Guo, On the simulation scalability of predicting residual stress and distortion in selective laser melting, J. Manuf. Sci. Engi.-Trans. ASME 140 (4) (2018), https://doi.org/10.1115/1.4038893.

[108] Nathan Charles Levkulich, An Experimental Investigation of Residual Stress Development during Selective Laser Melting of Ti-6Al-4V, Wright State University, 2017.

[109] M.B. Prime, A.T. DeWald, The contour method, practical residual stress measurement, Methods (2013) 109-138, https://doi.org/10.1002/9781118402832. ch5.

[110] P. Rangaswamy, M.L. Griffith, M.B. Prime, T.M. Holden, R.B. Rogge, J.M. Edwards, R.J. Sebring, Residual stresses in LENS ${ }^{\circledR}$ components using neutron diffraction and contour method, Mater. Sci. Eng., A 399 (1) (2005) 72-83.

[111] K. Wei, M. Lv, X. Zeng, Z. Xiao, G. Huang, M. Liu, J. Deng, Effect of laser remelting on deposition quality, residual stress, microstructure, and mechanical property of selective laser melting processed Ti-5Al-2.5 Sn alloy, Mater. Char. 150 (2019) 67-77, https://doi.org/10.1016/j.matchar.2019.02.010.

[112] J.P. Kruth, J. Deckers, E. Yasa, R. Wauthle, Assessing and comparing influencing factors of residual stresses in selective laser melting using a novel analysis method, Proc. Inst. Mech. Eng. Part B-J. Eng. Manuf. 226(B6) (2012) 980-991. https://doi org $/ 10.1177 / 0954405412437085$

[113] J. Saarimäki, M. Lundberg, J.J. Moverare, H. Brodin, 3D residual stresses in selective laser melted Hastelloy X, Icrs (2017)

[114] W. He, W. Shi, J. Li, H. Xie, In-situ monitoring and deformation characterization by optical techniques; part I: Laser-aided direct metal deposition for additive manufacturing, Opt. Lasers Eng. 122 (2019) 74-88, https://doi.org/10.1016/j. optlaseng.2019.05.020

[115] N.P. Calta, J. Wang, A.M. Kiss, A.A. Martin, P.J. Depond, G.M. Guss, V. Thampy, A.Y. Fong, J.N. Weker, K.H. Stone, C.J. Tassone, M.J. Kramer, M.F. Toney, A. Van Buuren, M.J. Matthews, An instrument for in situ time-resolved X-ray imaging and diffraction of laser powder bed fusion additive manufacturing processes, Rev. Sci. Instrum. 89 (5) (2018) 055101, , https://doi.org/10.1063/1.5017236.

[116] C. Zhao, K. Fezzaa, R.W. Cunningham, H. Wen, F. De Carlo, L. Chen, A.D. Rollett, T. Sun, Real-time monitoring of laser powder bed fusion process using high-speed X-ray imaging and diffraction, Sci. Rep. 7 (1) (2017) 3602, https://doi.org/10. 
1038/s41598-017-03761-2.

[117] R. Cunningham, C. Zhao, N. Parab, C. Kantzos, J. Pauza, K. Fezzaa, T. Sun, A.D. Rollett, Keyhole threshold and morphology in laser melting revealed by ultrahigh-speed x-ray imaging, Science 363 (6429) (2019) 849-852, https://doi. org/10.1126/science.aav4687.

[118] A.M. Korsunsky, M. Sebastiani, E. Bemporad, Residual stress evaluation at the micrometer scale: Aanalysis of thin coatings by FIB milling and digital image correlation, Surf. Coat. Technol. 205 (7) (2010) 2393-2403, https://doi.org/10. 1016/j.surfcoat.2010.09.033.

[119] D. Tomus, Y. Tian, P.A. Rometsch, M. Heilmaier, X.H. Wu, Influence of post heat treatments on anisotropy of mechanical behaviour and microstructure of Hastelloy-X parts produced by selective laser melting, Mater. Sci. Eng. A-Struct. Mater. Propert. Microstruct. Process. 667 (2016) 42-53, https://doi.org/10.1016/ j.msea.2016.04.086.

[120] L. Chao, R. White, X.Y. Fang, M. Weaver, Y.B. Guo, Microstructure evolution characteristics of Inconel 625 alloy from selective laser melting to heat treatment, Mater. Sci. Eng., A 705 (2017) 20-31, https://doi.org/10.1016/j.msea.2017.08. 058 .

[121] H. Li, M. Ramezani, M. Li, C. Ma, J. Wang, Effect of process parameters on tribological performance of $316 \mathrm{~L}$ stainless steel parts fabricated by selective laser melting, Manuf. Lett. 16 (2018) 36-39, https://doi.org/10.1016/j.mfglet.2018.04. 003.

[122] I.A. Roberts, Investigation of residual stresses in the laser melting of metal powders in additive layer manufacturing, University of Wolverhampton, 2012.

[123] M.J. Matthews, G. Guss, S.A. Khairallah, A.M. Rubenchik, P.J. Depond, W.E. King, Denudation of metal powder layers in laser powder bed fusion processes, Acta Mater. 114 (2016) 33-42, https://doi.org/10.1016/j.actamat.2016.05.017.

[124] M. Mohammad, R. Prahalada, Sensor-based build condition monitoring in laser powder bed fusion additive manufacturing process using a spectral graph theoretic approach, J. Manuf. Sci. Eng. 140(9) (2018) 091002.

[125] X. Zhou, D.Z. Wang, X.H. Liu, D.D. Zhang, S.L. Qu, J. Ma, G. London, Z.J. Shen, W. Liu, 3D-imaging of selective laser melting defects in a Co-Cr-Mo alloy by synchrotron radiation micro-CT, Acta Materialia 98 (2015) 1-16, https://doi.org/ 10.1016/j. actamat.2015.07.014

[126] S. Shrestha, T. Starr, K. Chou, A study of keyhole porosity in selective laser melting: single-track scanning with micro-CT analysis, J. Manuf. Sci. Eng.-Trans. ASME 141 (7) (2019) 1, https://doi.org/10.1115/1.4043622.

[127] S.V. Bael, G. Kerckhofs, M. Moesen, G. Pyka, J. Schrooten, J.P. Kruth, Micro-CTbased improvement of geometrical and mechanical controllability of selective laser melted Ti-6Al-4V porous structures, Mater. Sci. Eng., A 528 (24) (2011) 7423-7431, https://doi.org/10.1016/j.msea.2011.06.045.

[128] S. Tammas-Williams, H. Zhao, F. Leonard, F. Derguti, I. Todd, P.B. Prangnell, XCT analysis of the influence of melt strategies on defect population in Ti-6Al-4V components manufactured by Selective Electron Beam Melting, Mater. Charact. 102 (2015) 47-61, https://doi.org/10.1016/j.matchar.2015.02.008.

[129] C.B. Stutzman, A.R. Nassar, E.W. Reutzel, Multi-sensor investigations of optical emissions and their relations to directed energy deposition processes and quality, Addit. Manuf. 21 (2018) 333-339, https://doi.org/10.1016/j.addma.2018.03. 017

[130] B. Chris, M. Eric, C. Brett, P. Fred, Micron-level layer-wise surface profilometry to detect porosity defects in powder bed fusion of inconel 718, JOM 70 (9) (2018) 1844-1852, https://doi.org/10.1007/s11837-018-3025-7.

[131] G. Zhou, J. Kou, L. Yao, W. Zhu, C. Kai, N. Tamura, Quantitative scanning laue diffraction microscopy: application to the study of 3D printed nickel-based superalloys, Quantum Beam Sci. 2 (2) (2018) 13, https://doi.org/10.3390/ qubs2020013.

[132] T. Mishurova, S. Cabeza, K. Artzt, J. Haubrich, M. Klaus, C. Genzel, G. Requena, G. Bruno, An assessment of subsurface residual stress analysis in SLM Ti-6Al-4V, Materials 10 (4) (2017) 348.

[133] D.M. Hu, R. Kovacevic, Sensing, modeling and control for laser-based additive manufacturing, Int. J. Mach. Tools Manuf 43 (1) (2003) 51-60, https://doi.org/ 10.1016/S0890-6955(02)00163-3.

[134] H. Krauss, C. Eschey, M. Zaeh, Thermography for monitoring the selective laser melting process, in: Proceedings of the Solid Freeform Fabrication Symposium, 2012, pp. 999-1014.

[135] M. Montazeri, P. Rao, Sensor-based build condition monitoring in laser powder bed fusion additive manufacturing process using a spectral graph theoretic approach, J. Manuf. Sci. Eng. 140 (9) (2018), https://doi.org/10.1115/1.4040264.

[136] S. Berumen, F. Bechmann, S. Lindner, J.-P. Kruth, T. Craeghs, Quality control of laser- and powder bed-based Additive Manufacturing (AM) technologies, Phys. Procedia 5 (2010) 617-622, https://doi.org/10.1016/j.phpro.2010.08.089.

[137] T. Craeghs, S. Clijsters, E. Yasa, F. Bechmann, S. Berumen, J.-P. Kruth, Determination of geometrical factors in Layerwise Laser Melting using optical process monitoring, Opt. Lasers Eng. 49(12) (2011) 1440-1446. https:// doi.org/ 10.1016/j.optlaseng.2011.06.016.

[138] X. Zhao, D.W. Rosen, Experimental validation and characterization of a real-time metrology system for photopolymerization-based stereolithographic additive manufacturing process, Int. J. Adv. Manuf. Technol. 91 (1-4) (2016) 1255-1273, https://doi.org/10.1007/s00170-016-9844-1.

[139] X. Zhao, D.W. Rosen, Real-time interferometric monitoring and measuring of photopolymerization based stereolithographic additive manufacturing process: sensor model and algorithm, Meas. Sci. Technol. 28 (1) (2017) 015001, , https:// doi.org/10.1088/0957-0233/28/1/015001.

[140] S. Yoshida, T. Sasaki, M. Usui, S. Sakamoto, D. Gurney, I.K. Park, Residual stress analysis based on acoustic and optical methods, Materials (Basel) 9 (2) (2016) 112, https://doi.org/10.3390/ma9020112.
[141] H. Gaja, F. Liou, Defects monitoring of laser metal deposition using acoustic emission sensor, Int. J. Adv. Manuf. Technol. (2016) 1-14, https://doi.org/10. 1007/s00170-016-9366-x.

[142] J. Zhang, L. Zheng, X. Guo, V. Ji, V. Klosek, Residual stresses comparison determined by short-wavelength X-ray diffraction and neutron diffraction for 7075 aluminum alloy, J. Nondestr. Eval. 33 (1) (2014) 82-92, https://doi.org/10.1007/ s10921-013-0205-9.

[143] J.S. Robinson, C.E. Truman, S. Hossain, E.C. Oliver, D.J. Hughes, M.E. Fox, S51 Influence of cold compression on the residual stresses in 7449 forgings, Powder Diffr. 23 (2) (2016) 187 10.1154/1.2951814.

[144] J.P. Kruth, L. Froyen, J. Van Vaerenbergh, P. Mercelis, M. Rombouts, B. Lauwers, Selective laser melting of iron-based powder, J. Mater. Process. Technol. 149 (1-3) (2004) 616-622, https://doi.org/10.1016/j.jmatprotec.2003.11.051.

[145] P. Hanzl, M. Zetek, T. Baksa, T. Kroupa, The Influence of processing parameters on the mechanical properties of SLM parts, in: 25th Daaam International Symposium on Intelligent Manufacturing and Automation, 2014100 (2015) 1405-1413. https://doi.org/10.1016/j.proeng.2015.01.510.

[146] T. Vilaro, C. Colin, J.D. Bartout, As-fabricated and heat-treated microstructures of the Ti-6Al-4V alloy processed by selective laser melting, Metallurg. Mater. Trans. A-Phys. Metall. Mater. Sci. 42a (10) (2011) 3190-3199, https://doi.org/10.1007/ s11661-011-0731-y.

[147] K. Kempen, B. Vrancken, S. Buls, L. Thijs, J. Van Humbeeck, J.P. Kruth, Selective laser melting of crack-free high density M2 high speed steel parts by baseplate preheating, J. Manuf. Sci. Eng.-Trans. ASME 136 (6) (2014) 061026, , https://doi. org/10.1115/1.4028513.

[148] W. Li, J. Liu, Y. Zhou, S.F. Wen, Q.S. Wei, C.Z. Yan, Y.S. Shi, Effect of substrate preheating on the texture, phase and nanohardness of a Ti-45Al-2Cr-5Nb alloy processed by selective laser melting, Scr. Mater. 118 (2016) 13-18, https://doi org/10.1016/j.scriptamat.2016.02.022.

[149] D. Buchbinder, W. Meiners, N. Pirch, K. Wissenbach, J. Schrage, Investigation on reducing distortion by preheating during manufacture of aluminum components using selective laser melting, J. Laser Appl. 26 (1) (2014) 012004, , https://doi. org/10.2351/1.4828755.

[150] B.U.J.C. Vrancken, S.U. Buls, J.P.U. Kruth, J.U.J. Van Humbeeck, Influence of preheating and oxygen content on Selective Laser Melting of Ti-6Al-4V, Proceedings of the 16th RAPDASA Conference, (2015).

[151] R. Mertens, B. Vrancken, N. Holmstock, Y. Kinds, J.P. Kruth, J. Van Humbeeck, Influence of powder bed preheating on microstructure and mechanical properties of H13 tool steel SLM parts, in: Laser Assisted Net Shape Engineering 9 International Conference on Photonic Technologies Proceedings of the Lane 2016 83 (2016) 882-890. https://doi.org/10.1016/j.phpro.2016.08.092.

[152] H. Ali, L. Ma, H. Ghadbeigi, K. Mumtaz, In-situ residual stress reduction, martensitic decomposition and mechanical properties enhancement through high temperature powder bed pre-heating of Selective Laser Melted Ti-6Al-4V, Mater. Sci. Eng. A-Struct. Mater. Propert. Microstruct. Process. 695 (2017) 211-220, https://doi.org/10.1016/j.msea.2017.04.033.

[153] M. Maly, C. Holler, M. Skalon, B. Meier, D. Koutny, R. Pichler, C. Sommitsch, D. Palousek, Effect of process parameters and high-temperature preheating on residual stress and relative density of Ti-6Al-4V processed by selective laser melting, Materials (Basel) 12 (6) (2019), https://doi.org/10.3390/ma12060930.

[154] B. Vrancken, S. Buls, J.P. Kruth, J.V. Humbeeck, Preheating of selective lase melted Ti- 6Al-4V: microstructure and mechanical properties, Proceedings of the 13th World Conference on Titanium, Wiley Online Library, 2016, pp. 1269-1277.

[155] D. Buchbinder, W. Meiners, K. Wissenbach, K. Müller-Lohmeier, E. Brandl, N. Skrynecki, Rapid manufacturing of aluminium parts for serial production via selective laser melting (SLM), International Conference on Rapid Manufacturing, (2008).

[156] R. Mertens, S. Dadbakhsh, J. Van Humbeeck, J.-P. Kruth, Application of base plate preheating during selective laser melting, Procedia CIRP 74 (2018) 5-11.

[157] L.E. Murr, S.M. Gaytan, D.A. Ramirez, E. Martinez, J. Hernandez, K.N. Amato, P.W. Shindo, F.R. Medina, R.B. Wicker, Metal fabrication by additive manufacturing using laser and electron beam melting technologies, J. Mater. Sci. Technol. 28 (1) (2012) 1-14, https://doi.org/10.1016/S1005-0302(12)60016-4.

[158] B. Vrancken, L. Thijs, J.P. Kruth, J. Van Humbeeck, Heat treatment of Ti-6Al-4V produced by Selective Laser Melting: microstructure and mechanical properties, J. Alloy. Compd. 541 (2012) 177-185, https://doi.org/10.1016/j.jallcom.2012.07. 022 .

[159] S.V. Kuryntsev, The influence of pre-heat treatment on laser welding of T-joints of workpieces made of selective laser melting steel and cold rolled stainless steel, Opt. Laser Technol. 107 (2018) 59-66, https://doi.org/10.1016/j.optlastec.2018. 05.031.

[160] J. Song, Q. Tang, Q.X. Feng, S. Ma, R. Setchi, Y. Liu, Q.Q. Han, X.J. Fan, M.X. Zhang, Effect of heat treatment on microstructure and mechanical behaviours of $18 \mathrm{Ni}-300$ maraging steel manufactured by selective laser melting, Opt. Laser Technol. 120 (2019) 105725, , https://doi.org/10.1016/j.optlastec.2019.105725.

[161] A. Kreitcberg, V. Brailovski, S. Turenne, Effect of heat treatment and hot isostatic pressing on the microstructure and mechanical properties of Inconel 625 alloy processed by laser powder bed fusion, Mater. Sci. Eng. A-Struct. Mater. Propert. Microstruct. Process. 689 (2017) 1-10, https://doi.org/10.1016/j.msea.2017.02. 038.

[162] C. Tian, L. Wang, T. Sheng, Effects of vacuum annealing treatment on microstructures and residual stress of AlSi10Mg parts produced by selective laser melting process, Mod. Phys. Lett. B 30 (19) (2016) 1650255, https://doi.org/10. 1142/S0217984916502559.

[163] S.L. Sing, S. Huang, W.Y. Yeong, Effect of solution heat treatment on microstructure and mechanical properties of laser powder bed fusion produced cobalt- 
28chromium-6molybdenum, Mater. Sci. Eng., A 769 (2020) 138511, , https://doi. org $/ 10.1016 /$ j.msea.2019.138511.

[164] A.R. Nassar, J.S. Keist, E.W. Reutzel, T.J. Spurgeon, Intra-layer closed-loop control of build plan during directed energy additive manufacturing of Ti-6Al-4V, Addit. Manuf. 6 (2015) 39-52, https://doi.org/10.1016/j.addma.2015.03.005.

[165] E.W. Reutzel, A.R. Nassar, A survey of sensing and control systems for machine and process monitoring of directed-energy, metal-based additive manufacturing, Rapid Prototyp. J. 21 (2) (2015) 159-167, https://doi.org/10.1108/Rpj-12-20140177.

[166] G. Tapia, A. Elwany, A review on process monitoring and control in metal-based additive manufacturing, J. Manuf. Sci. Eng.-Trans. ASME 136 (6) (2014) 060801, , https://doi.org/10.1115/1.4028540.

[167] L. Clemon, Material Quality and Process Monitoring in Metal Additive Manufacturing, UC Berkeley, 2017.

[168] Z.Y. Chua, I.H. Ahn, S.K. Moon, Process monitoring and inspection systems in metal additive manufacturing: status and applications, Int. J. Precis. Eng. Manuf.Green Technol. 4 (2) (2017) 235-245, https://doi.org/10.1007/s40684-0170029-7.

[169] M. Mani, B.M. Lane, M.A. Donmez, S.C. Feng, S.P. Moylan, A review on measurement science needs for real-time control of additive manufacturing metal powder bed fusion processes, Int. J. Prod. Res. 55 (5) (2017) 1400-1418, https:// doi.org/10.1080/00207543.2016.1223378.

[170] N. Kalentics, E. Boillat, P. Peyre, S. Ciric-Kostic, N. Bogojevic, R.E. Loge, Tailoring residual stress profile of Selective Laser Melted parts by Laser Shock Peening, Addit. Manuf. 16 (2017) 90-97, https://doi.org/10.1016/j.addma.2017.05.008.

[171] M.A.S. Torres, H.J.C. Voorwald, An evaluation of shot peening, residual stress and stress relaxation on the fatigue life of AISI 4340 steel, Int. J. Fatigue 24 (8) (2002) 877-886, https://doi.org/10.1016/S0142-1123(01)00205-5.

[172] X. Xing, X. Duan, X. Sun, H. Gong, L. Wang, F. Jiang, Modification of residual stresses in laser additive manufactured AlSi10Mg specimens using an ultrasonic peening technique, Materials (Basel) 12(3) (2019) 455. https://doi.org/10.3390/ ma12030455.

[173] X.D. Xing, X.M. Duan, T.T. Jiang, J.D. Wang, F.C. Jiang, Ultrasonic peening treatment used to improve stress corrosion resistance of AlSi10Mg components fabricated using selective laser melting, Metals 9 (1) (2019), https://doi.org/10. 3390/met9010103.

[174] H. Yamaguchi, O. Fergani, P.Y. Wu, Modification using magnetic field-assisted finishing of the surface roughness and residual stress of additively manufactured components, Cirp Ann.-Manuf. Technol. 66 (1) (2017) 305-308, https://doi.org/ 10.1016/j.cirp.2017.04.084.

[175] F. Lambiase, S. Genna, C. Leone, Laser finishing of 3D printed parts produced by material extrusion, Opt. Lasers Eng. 124 (2020) 105801, , https://doi.org/10. 1016/j.optlaseng.2019.105801.

[176] O. Oyelola, P. Crawforth, R. M'Saoubi, A.T. Clare, On the machinability of directed energy deposited Ti-6Al-4V, Addit. Manuf. 19 (2018) 39-50, https://doi.org/10. 1016/j.addma.2017.11.005.

[177] H.K.D.H. Bhadeshia, Developments in martensitic and bainitic steels: role of the shape deformation, Mater. Sci. Eng A-Struct. Mater. Propert. Microstruct. Process.
378 (1-2) (2004) 34-39, https://doi.org/10.1016/j.msea.2003.10.328.

[178] J.A. Francis, H.K.D.H. Bhadeshia, P.J. Withers, Welding residual stresses in ferritic power plant steels, Mater. Sci. Technol. 23 (9) (2007) 1009-1020, https://doi.org/ 10.1179/174328407x213116.

[179] A.A. Shirzadi, H.K.D.H. Bhadeshia, L. Karlsson, P.J. Withers, Stainless steel weld metal designed to mitigate residual stresses, Sci. Technol. Weld. Join. 14 (6) (2009) 559-565, https://doi.org/10.1179/136217109x437178.

[180] J.A. Francis, H.J. Stone, S. Kundu, H.K.D.H. Bhadeshia, R.B. Rogge, P.J. Withers, L. Karlsson, The Effects of filler metal transformation temperature on residual stresses in a high strength steel weld, J. Press. Vessel Technol.-Trans. ASME 131 (4) (2009) 041401, , https://doi.org/10.1115/1.3122036.

[181] H. Murakawa, M. Beres, C.M. Davies, S. Rashed, A. Vega, M. Tsunori, K.M. Nikbin, D. Dye, Effect of low transformation temperature weld filler metal on welding residual stress, Sci. Technol. Weld. Join. 15 (5) (2010) 393-399, https://doi.org/ 10.1179/136217110x12714217309614.

[182] P. Vora, R. Martinez, N. Hopkinson, I. Todd, K. Mumtaz, Customised alloy blends for in-situ Al339 alloy formation using anchorless selective laser melting, Technologies 5 (2) (2017) 24, https://doi.org/10.3390/technologies5020024.

[183] M.L. Montero-Sistiaga, R. Mertens, B. Vrancken, X. Wang, B. Van Hooreweder, J.P. Kruth, J. Van Humbeeck, Changing the alloy composition of Al7075 for better processability by selective laser melting, J. Mater. Process. Technol. 238 (2016) 437-445.

[184] L.V. Belle, G. Vansteenkiste, J.C. Boyer, Investigation of residual stresses induced during the selective laser melting process, Key Eng. Mater. 554-557 (2013) (2013) 1828-1834.

[185] R. Baskett, Effects of Support Structure Geometry on SLM Induced Residual Stresses in Overhanging Features (2017).

[186] L. Wang, X. Jiang, Y. Zhu, Z. Ding, X. Zhu, J. Sun, B. Yan, Investigation of performance and residual stress generation of AlSi10Mg processed by selective lase melting, Adv. Mater. Sci. Eng. (2018).

[187] J.C.H. Erik R. Denlinger, Pan Michaleris, T.A. Palmer, Effect of inter-layer dwell time on distortion and residual stress in additive manufacturing of titanium and nickel alloys, J. Mater. Process. Technol. 215 (2015) 123-131. https://doi.org/ https://doi.org/10.1016/j.jmatprotec.2014.07.030.

[188] D. Gu, H. Chen, Selective laser melting of high strength and toughness stainless steel parts: The roles of laser hatch style and part placement strategy, Mater. Sci. Eng., A 725 (2018) 419-427, https://doi.org/10.1016/j.msea.2018.04.046.

[189] W. Yu, S.L. Sing, C.K. Chua, X. Tian, Influence of re-melting on surface roughness and porosity of AlSi10Mg parts fabricated by selective laser melting, J. Alloy. Compd. 792 (2019) 574-581, https://doi.org/10.1016/j.jallcom.2019.04.017.

[190] K.G. Prashanth, S. Scudino, T. Maity, J. Das, J. Eckert, Is the energy density a reliable parameter for materials synthesis by selective laser melting? Mater. Res. Lett. 5 (6) (2017) 386-390, https://doi.org/10.1080/21663831.2017.1299808.

[191] A.M. Khorasani, I. Gibson, A. Ghasemi, A. Ghaderi, A comprehensive study on variability of relative density in selective laser melting of Ti-6Al-4V, Virt. Phys. Prototyp. 14 (4) (2019) 349-359, https://doi.org/10.1080/17452759.2019. 1614198 